NBER WORKING PAPER SERIES

\title{
AGGREGATE IMPLICATIONS OF LABOR MARKET DISTORTIONS: THE RECESSION OF 2008-9 AND BEYOND
}

\author{
Casey B. Mulligan \\ Working Paper 15681 \\ http://www.nber.org/papers/w15681 \\ NATIONAL BUREAU OF ECONOMIC RESEARCH \\ 1050 Massachusetts Avenue \\ Cambridge, MA 02138 \\ January 2010
}

I appreciate the comments of Andrei Shleifer, seminar participants at Clemson University, Tel Aviv University, and students at M.I.T. I will provide updates on my blog www.panic2008.net. I appreciate the financial support of the George J. Stigler Center for the Study of the Economy and the State. The views expressed herein are those of the author and do not necessarily reflect the views of the National Bureau of Economic Research.

NBER working papers are circulated for discussion and comment purposes. They have not been peerreviewed or been subject to the review by the NBER Board of Directors that accompanies official NBER publications.

(C) 2010 by Casey B. Mulligan. All rights reserved. Short sections of text, not to exceed two paragraphs, may be quoted without explicit permission provided that full credit, including $\odot$ notice, is given to the source. 
Aggregate Implications of Labor Market Distortions: The Recession of 2008-9 and Beyond

Casey B. Mulligan

NBER Working Paper No. 15681

January 2010

JEL No. E13,E24,E32,O41

\begin{abstract}
$\underline{\text { ABSTRACT }}$
The aggregate neoclassical growth model - with a labor income tax or "labor market distortion" that began growing at the end of 2007 as its only impulse - produces time series for aggregate labor usage, consumption, investment, and real GDP that closely resemble actual U.S. time series. Of particular interest is the fact that the model - with no explicit financial market - has investment fall steeply during the recession not because of any distortions with the supply of capital, but merely because labor is falling and labor is complementary with capital in the production function. Through the lens of the model, the fact the real consumption fell significantly below trend during 2008 suggests that labor usage per capita could get somewhat lower than it was at the end of 2009, and is expected to remain below pre-recession levels even after the "recovery."
\end{abstract}

\author{
Casey B. Mulligan \\ University of Chicago \\ Department of Economics \\ 1126 East 59th Street \\ Chicago, IL 60637 \\ and NBER \\ c-mulligan@uchicago.edu
}


The market economies of the U.S. and other countries have dramatically cut back their labor usage, measured both in absolute terms and relative to real output. Roughly coincident with the collapse of labor usage was a crisis in financial markets. To what degree was the financial market crisis a reaction to, and anticipation of, the labor collapse? Or did the financial crisis create unemployment? Answers to these questions are important because they go to the heart of the recession's causes, and speak to the role of government in affecting the economy's path.

Limiting the supply of aggregate investment is one mechanism for financial markets to impact the rest of the economy, and in fact real investment fell through the first year and a half of this recession. In this case, one notable effect of financial crisis would be to reduce aggregate investment below (and increase consumption above) what is efficient given the labor employed. Alternatively, financial crisis or something else could reduce labor usage more directly, and investment would respond to put the capital stock on a path that is consistent with the lesser amount of labor usage. To contribute to the bigger questions posed above, this paper considers whether a single shock to the labor market in a simple aggregate model - without explicit financial markets - would produce dynamics that resemble this recession's measured dynamics and, if so, how such a "labor shock" recession would end. The results offer one barometer for gauging the relative importance of various explanations for the actual recession.

In modeling a recession as a transition to an increasingly distorted labor market, I assume that production and capital markets are always efficient (or at least as efficient as they were before the recession), so that their dynamics are understood as mere reactions to the labor market distortions. In the short run, consumption, investment, and labor all decline, albeit in different proportions. Labor declines in the short run, because (by 
construction) the recession's sole cause is a labor market distortion. Consumption declines because of the permanent income effect. Thanks to the legacy of a capital stock accumulated prior to the labor market distortion, the marginal product of capital falls with the workforce, which creates an intertemporal substitution effect on consumption partially offsetting the permanent income effect. Thus, consumption declines less than labor in the short run, regardless of whether the labor distortion is temporary or permanent. For the same reason that the marginal product of capital falls, the marginal and average products of labor initially rise.

If the labor distortion is long lasting, the labor reduction will be long lasting and investment will be low for long enough to eventually reduce the capital stock by the same proportion as labor. Once the labor distortion stabilizes at its new higher level, the marginal product of capital can rise again, and reduce the intertemporal substitution effect that had mitigated the consumption decline. After enough time has passed with the higher labor distortion in place, labor, consumption, and capital have all been reduced in the same proportions.

The paths for consumption and investment that are efficient in the model given a long-lasting labor distortion are compared with the monthly and quarterly aggregate time series since December 2007, when this recession began. The model and data agree that investment expenditure would fall 25-30 percent, although the data show investment dropping about three quarters sooner than predicted by the model. If labor is expected to be depressed for a long time to come, consumption dynamics in the model are similar to those in the data. In this sense, a large majority of this recession's consumption dynamics and investment decline were a reaction to, and anticipation of, low levels of labor usage.

Consistent with the model, the percentage consumption decline has so far been much less than the percentage decline in work hours. Total factor productivity has not significantly deviated from prior trends. Real wages per hour and labor productivity have risen in absolute terms, and relative to prior trends. A large and obvious "labor wedge" has emerged during this recession (Mulligan, 2009a).

If the labor distortion is expected to eventually return to its pre-recession value in the not-too-distant future, consumption and capital will never get as low as labor while 
the distortion lasts. Thus, under the assumption the recession is solely caused by a labor market distortion, the consumption and investment responses indicate how long the labor distortion and the low levels of labor usage are expected to remain. Through the lens of the model, it appears that labor usage will average five or six percent below the previous trend for the indefinite future (now it is about 10 percent below trend), and will not return to the previous trend for quite a long time. Even if the model were known to be correct, it is more difficult to predict, on the basis of aggregate behavior so far, whether the average 5-6 percent below trend will be achieved through still further declines in the short run followed by a subsequent increase, or whether labor will follow the previous trend from here.

The aggregate implications of labor distortions are interesting in their own right because a number of public and private sector actions new to this recession are expected to distort the labor market. To mention a few, the federal minimum wage was hiked three times in and around this recession. Labor market search frictions are arguably greater than usual. Prices fell during the recession, and perhaps wages did not adequately adjust with them. A large number of homeowners owed more on their mortgage than their house was worth, and both private and public sector renegotiations of the mortgage contracts have served as a massive implicit tax on earning during the recession (Mulligan, 2009b). Renegotiations of business debts (Jermann and Quadrini, 2009), student loans, and tax debts present debtors with similar disincentives. The new home buyers $\$ 8000$ tax credit is phased out as annual family income varies from $\$ 80,000$ to $\$ 120,000$. Arguably, the 2008 election was associated with an increase in the power of unions to shape public policy, and thereby the labor market. Congress has considered various legislation that would raise marginal income tax rates, and would present Americans with new health benefits that would be phased out as a function of income.

Some of these distortions are temporary - for example, the phenomenon of underwater mortgages is likely temporary as mortgages are renegotiated and nominal housing prices eventually rise. Others of the distortions are essentially an expansion of the welfare state, and are therefore expected to be longer lived. However, given the multitude of events that are shaping incentives, and the complexity of each one of them, we are not yet in a position to quantify the cumulative incentive effects of these events, 
and the degree to which actual labor usage has been restricted for supply versus demand reasons. Thus, this paper assumes that the time series of the cumulative incentive effects of whatever may be distorting the labor market is enough to put labor usage on a path like the one we observe from December 2007 to October 2009 (the most recent data available). With that assumption, the paper then examines the efficient response of the rest of the economy to these distortions, and compares that response to actual experience.

\section{The Neoclassical Growth Model with a Labor Market Distortion}

The neoclassical growth model with a labor distortion $\tau$ is described by three equilibrium conditions at any point in time, two of which are not directly affected by the labor distortion. The first condition says that gross output is produced with capital and labor, and is (exhaustively) used for consumption and gross investment.

$$
A n_{t}^{\alpha} k_{t}^{1-\alpha}=c_{t}+\dot{k}_{t}+\delta k_{t}
$$

where $n$ denotes labor input, and $k$ capital input, each relative to a constant exponential trend that reflects the constant exogenous growth rates for population and technology (Barro and Sala-i-Martin, 2003). $t$ is the time subscript and $A>0$ and $\alpha \in(0,1)$ are constant technology parameters. Dots denote time derivatives, and $\delta>0$ reflects the rate of capital depreciation as well as population growth and rates of technical progress.

The second condition says that the marginal rate of substitution of consumption over time is equal to the marginal product of capital net of depreciation.

$$
\text { IMRS }_{t}=(1-\alpha) A\left(n_{t} / k_{t}\right)^{\alpha}-\delta
$$

Many studies have put a wedge in condition (1) by letting the productivity parameter vary over time. Other studies have also put a wedge in the intertemporal condition (2), perhaps with a rate of time preference or price of investment goods that varies over time. But the thesis of this paper is that a large fraction of this recession can 
be understood as a consequence of a time-vary labor wedge alone, so I have omitted those possible sources of time-variation.

The third condition has the labor distortion $\tau$, and says that the marginal rate of substitution between consumption and leisure is less than the marginal product of labor by $100 \tau$ percent:

$$
M P L_{t}=\left(1-\tau_{t}\right) \alpha A\left(k_{t} / n_{t}\right)^{1-\alpha}
$$

where $\tau_{t} \leq 1$ for all $t$. The labor distortion includes the some effects of distortionary taxes, labor market regulations (Mulligan, 2002, 2005), other market distortions (Gali, Gertler, and Lopez-Salido, 2007; Shimer, 2009), as well as errors in the specification of the marginal rate of substitution function (Parkin, 1988; Hall, 1997).

I assume that preferences are a time-invariant additively separable isoelastic function over time and between consumption and leisure. The marginal rates of substitution become

$$
\begin{aligned}
\operatorname{IMRS}_{t} & \equiv \frac{1}{\sigma}\left(\frac{\dot{c}_{t}}{c_{t}}\right)+\rho \\
M R S_{t} & \equiv \gamma c_{t}^{1 / \sigma} n_{t}^{1 / \eta}
\end{aligned}
$$

where $\sigma$ is the constant elasticity of substitution of consumption over time, $\eta$ is the constant Frisch elasticity of labor supply, $\rho$ is the constant rate of time preference (which may also reflect exogenous growth rates of population and technology), and $\gamma$ is a constant parameter dictating the relative preference for leisure. In order to rule out unrealistically large intertemporal substitution effects, I make the weak assumption that $\sigma \leq 1 /(1-\alpha)^{2}$

The functional form (5) for the marginal rate of substitution function has been occasionally used in the macroeconomics literature, although for different reasons. My purposes here are simplicity - the form (5) has a constant Frisch elasticity of labor supply, $\eta$ - and to have consumption, capital, and labor all change in the same

\footnotetext{
${ }^{2}$ For example, with $\alpha=0.7$, this upper bound on the intertemporal substitution elasticity $\sigma$ is 3.3 .
} 
proportions in the long run. ${ }^{3}$ To the extent that the marginal product of capital has varied over this recession, the assumed functional form for the intertemporal marginal rate of substitution has some effect on the degree to which the model matches the data. However, the claim of this paper is "merely" that there exists a simple one-shock model that fits the aggregate data well, whereas this kind of sensitivity analysis would suited to confirm a different claim: about the range of models that might fit the aggregate data.

With these definitions, the capital and labor market equilibrium conditions become:

$$
\begin{gathered}
\dot{c}_{t}=\sigma\left[(1-\alpha) A\left(n_{t} / k_{t}\right)^{\alpha}-\delta-\rho\right] c_{t} \\
n_{t}^{1 / \eta}=\frac{1-\tau_{t}}{\gamma} \frac{\alpha A}{c_{t}^{1 / \sigma}}\left(k_{t} / n_{t}\right)^{1-\alpha}
\end{gathered}
$$

Given a time path for the labor distortion, an equilibrium is a time path for consumption, a time path for work, and a time path for capital that, for all $t \geq 0$, solve the dynamical system (1) and (6), and the satisfy the labor market condition (7), the usual transversality condition, and the given initial capital stock. ${ }^{4}$ Note that the parameter $\sigma$ is the effect of the marginal product of capital on consumption growth, and would be properly calibrated from pre-recession data comparing the marginal product of capital with consumption growth. ${ }^{5}$

\footnotetext{
${ }^{3}$ Another functional form commonly used in the real business cycle literature - Cobb-Douglas in consumption and leisure - has constant proportional long run effects on consumption and leisure.

${ }^{4}$ If it were not for my assumption that the preference parameter is constant over time, the preference parameter $\gamma$ would be observationally equivalent to the labor wedge $\tau$ because both enter the system only through the labor market condition (7), and both do so in a multiplicative way (see Mulligan 2005 on these alternative explanations for the labor wedge). For the purpose of this paper, I interpret the wedge to include the combined effects of labor preferences and actual labor market distortions, and do not attempt to distinguish them.

${ }^{5}$ Only if the promised interest rate of government bonds fluctuated closely with the marginal product of capital, could $\sigma$ be measured as the effect of government bond yields on consumption growth. [cite Mulligan]
} 


\section{Dynamics of the Stationary System}

If the labor distortion were constant over time, the dynamical system is saddle path stable, with only the saddle path satisfying the transversality condition. The stationary state of the system $\left(c_{s s}, k_{s s}, n_{s s}\right)$ has a closed form solution:

$$
\begin{gathered}
k_{s s}^{1 / \eta+1 / \sigma}=\frac{1-\tau}{\gamma} \frac{\alpha}{(\delta+\rho)^{(1 / \eta+1) / \alpha-1}(\alpha \delta+\rho)^{1 / \sigma}} A^{(1 / \eta+1) / \alpha}(1-\alpha)^{(1 / \eta+1) / \alpha-1+1 / \sigma} \\
(1-\alpha) A\left(n_{s s} / k_{s s}\right)^{\alpha}=\delta+\rho \\
c_{s s}=\frac{\alpha \delta+\rho}{1-\alpha} k_{s s}
\end{gathered}
$$

The last two equations in (8) determine the steady state ratio of consumption and work to the capital stock, and do not depend on the value for the labor distortion. Thus, a permanent increase in the labor distortion reduces the long run capital stock, and reduces consumption and work in the same proportion. ${ }^{6}$

When the labor distortion is constant, the simplest form of the phase diagram for saddle path stable systems describes the dynamics of the system from any initial capital stock. The $\dot{k}=0$ schedule in the $[k, c]$ plane is implicitly defined by:

$$
\begin{gathered}
c=\left[A N(c, k ; 1-\tau)^{\alpha}-\delta\right] k \\
N(c, k ; 1-\tau)^{1-\alpha+1 / \eta} \equiv \frac{1-\tau}{\gamma} \frac{\alpha A}{c^{1 / \sigma} k^{1 / \eta}}
\end{gathered}
$$

where $N(c, k ; 1-\tau)$ is the labor-capital ratio that satisfies the labor market condition (7) for given values of consumption, capital, and the labor distortion. Along $\dot{k}=0$, consumption equals net output, so the schedule slopes up if and only if net output increases with capital, taking into account the positive effect of capital on labor for a given marginal utility of consumption. The maximum of this schedule therefore occurs at a capital stock that exceeds the "golden rule" capital stock that maximizes net output for a given labor, which itself exceeds the steady state capital stock for which the marginal product of

\footnotetext{
${ }^{6}$ See also Prescott's (2004) analysis of the steady states of such a model in order to understand how the European and American economies differ.
} 
capital equals the rate of time preference $\rho$. A larger value for the labor distortion $\tau$ is associated with a $\dot{k}=0$ schedule that is lower at each value of $k$.

The $\dot{c}=0$ schedule is implicitly defined by:

$$
N(c, k ; 1-\tau)^{\alpha}=\frac{\delta+\rho}{1-\alpha} \frac{1}{A}
$$

Thus, the schedule slopes down and has elasticity equal to $-\sigma / \eta$. A larger value for the labor distortion $\tau$ is associated with a $\dot{c}=0$ schedule that is lower at each value of $k$.

Figure 1 shows $\dot{c}=0$ and $\dot{k}=0$ schedules and the implied dynamics of the system. When capital is below (above) its steady state value, there is an initial value for consumption that is necessarily below (above) its steady state value so that the dynamics of the system asymtotically approach the steady state. Proposition 1 characterizes the stable manifold containing such paths.

Proposition 1. If $\sigma \in\left(0,(1-\alpha)^{-1}\right)$, the stable manifold of the system slopes up in the $[k, c]$ plane and crosses the ray from origin from above.

Proof In the $[k, c]$ plane, both the stable and unstable manifolds solve the ordinary differential equation

$$
\begin{gathered}
c^{\prime}(k)=\sigma \frac{(1-\alpha) A N(c(k), k ; 1-\tau)^{\alpha}-\delta-\rho}{A N(c(k), k ; 1-\tau)^{\alpha}-\delta-c(k) / k} \frac{c(k)}{k} \\
N(c(k), k ; 1-\tau)^{1-\alpha+1 / \eta} \equiv \frac{1-\tau}{\gamma} \frac{\alpha A}{c^{1 / \sigma} k^{1 / \eta}}
\end{gathered}
$$

The elasticity of these two manifolds in the neighborhood of the steady can be found by using L'Hopital's rule and noting that the resulting quadratic equation is satisfied for both elasticities. One of the quadratic equation's solutions is in the interval $(0,1){ }^{7}$ while the other is in $(-\infty, 1)$. The unstable manifold's elasticity corresponds to the smaller solution, which means that the elasticity of the stable manifold at the steady state is in $(0,1)$. The steady state lies on the ray from origin, which means that the stable manifold crosses that ray at the steady state from above.

For any capital stock below (above) its steady state value, the stable manifold is below (above) the $\dot{k}=0$ schedule, which implies that equation (11)'s denominator is

\footnotetext{
${ }^{7}$ To prove this, note that the large quadratic root increases with $\sigma$, is 0 at $\sigma=0$, and is one at $\sigma=(1-\alpha)^{-1}$.
} 
positive (negative), respectively. At the steady state, the numerator is zero and the manifold slopes up. Because the net marginal product of capital term in the numerator declines in both $c$ and $k$, it would be positive (negative) even if $c^{\prime}(k)$ were zero, which means that $c^{\prime}(k)$ is positive for any capital stock less (greater) than the steady state, respectively.

A number of analytical results can be obtained for this model. Some of the results are better displayed numerically, in which case parameter values are assumed as in shown in Table 1 below (Appendix II has more on calibration).

\section{III.Short Run Effects of a Permanent and Immediate Increase in the Labor Distortion}

$\underline{\text { Proposition } 2}$ A permanent labor distortion would reduce the steady state capital stock, effort, and consumption in the same proportions.

Figure 2 shows the steady states and stable manifolds of the stationary system with labor distortion $\tau$ and the stationary system with labor distortion $\tau^{\prime}>\tau$. Because the steady states lie on the same ray from the origin, and both stable manifolds cross that ray from above, the stable manifold corresponding to the smaller distortion lies above that corresponding to the larger distortion. ${ }^{8}$

Lemma If $\sigma \in\left(0,(1-\alpha)^{-1}\right)$, the elasticity of labor with respect to capital is less than the elasticity of consumption with respect to capital along the stable manifold of the stationary system.

Proof See Appendix I.

\footnotetext{
${ }^{8}$ They cannot cross. To prove this, suppose not: they cross at $(k, c)$ with $k>k_{s s}$ and the stable manifold corresponding to the smaller distortion crossing from above. The labor-capital ratio $N$ must be greater on the small distortion manifold. From equation (11), this means that the stable manifold for the smaller distortion is steeper, which is a contradiction.
} 
Proposition 3 If $\sigma \in\left(0,(1-\alpha)^{-1}\right)$, the initial effects of a permanent and immediate labor distortion are to reduce labor and consumption, but consumption declines in a lesser proportion.

Proof As shown in Proposition 2, the steady state consumption and labor impacts are in the same proportion. Because the initial capital stock exceeds the steady state capital stock, initial consumption must exceed steady state consumption. Initial labor may (or may not, depending on parameter values) exceed steady state labor, but the Lemma guarantees that the percentage gap between initial and steady state is greater for consumption.

A closed-form, albeit cumbersome, formula for the ratio $\theta$ of the initial change in log consumption to the initial change in log labor can be calculated in the locality of the steady state. Figure 3 below displays values for $\theta$ as a function of the intertemporal substitution elasticity $\sigma$ and the labor supply elasticity $\eta$, using assumed values for the parameters shown in Table 1. ${ }^{9}$ The initial change in log consumption is not sensitive to the labor supply elasticity, but (as a percentage of the initial change in log labor) does range from 20 to 50 percent depending on the intertemporal substitution elasticity. Thus, the result labor's initial decline is at least twice as much as consumption's when the shock comes from a greater labor distortion holds for a wide range of parameter values, despite the fact that in the long run both labor and consumption decline by the same percentage.

\section{The Gradual Emergence of a Permanent Distortion}

The sudden and immediate emergence of a permanent labor distortion is intellectually cumbersome because it combines two types of initial effects: the wealth effect of the news that the present value of output is less than previously thought, and the substitution effect of the initial distortion creating an increase in leisure and a reduction in consumption. More important, the actual distortions in the economy may accumulate

\footnotetext{
${ }^{9}$ For small changes in the amount of labor market distortion, $\theta$ does not depend on the level of the distortion.
} 
continuously as, for example, the housing market continuously deteriorates, or various cumulatively distorting public policies are introduced at staggered dates.

For this reason, I consider a labor market distortion that evolves continuously with time. At time $T$, the distortion reaches its long value, which I assume exceeds its initial value. Two types of dynamics are possible, depending on whether, and how much, the peak distortion exceeds the long run distortion. I consider each case separately.

\section{A. A Gradual Monotone Transition}

Suppose that the distortion increases continuously and monotonically with time for $T$ years, and then remains forever after $T$ at that higher level, as shown in Figure 4. As of time $T$, the system must be on the stable manifold corresponding to the long run value for the distortion, which is shown in Figure 2 as a black curve. Consumption cannot jump any time after time zero, so time paths for consumption and capital prior to time $T$ satisfy the differential equations (1) and (6), satisfy the labor market condition (7) for the distortion amount assumed at each date, satisfy the given initial capital stock, and terminate at time $T$ at an allocation $[k(T), c(T)]$ that is on the stable manifold of the stationary system with high distortion level. Furthermore, as shown in Figure 2's green curve, the time path in the $[k, c]$ plane approaches the stable manifold from above because the labor distortion is less before time $T$ than at time $T .{ }^{10}$

Not surprisingly, the initial reduction in consumption is less than it would be if the entire distortion change occurred immediately at time 0 , because the wealth and substitution effects on labor supply are both smaller in this case. Labor initially increases a bit, because of the adverse wealth effect and the fact that little distortion is initially present to create a substitution effect. The initial labor increase raises the marginal product of capital and consumption growth (after consumption's initial jump down), which motivates some investment in the short run. As the labor distortion accumulates, labor, investment, and consumption growth fall. The length of the initial high-labor period depends on the size relative wealth and substitution effects on labor supply, and how quickly the labor distortion approaches its long run value.

\footnotetext{
${ }^{10}$ For a formal proof, differentiate $c^{\prime}(k)$ as shown in equation (11) with respect to the distortion $\tau$, holding $c$ and $k$ constant, and note that this derivative is negative.
} 
Between time zero and time $T$ - as the labor distortion has partially emerged - an observer might wonder how much worse the distortion will get. The answer to this question is revealed by labor and consumption behavior: labor and consumption growth above (below) steady state values means that the distortion will (will not) get significantly larger. In other words, the fact that more labor is used in the face of a greater labor market distortion reveals that agents are attempting to save in preparation for a still worse labor distortion.

Using the benchmark parameter values shown in Table 1 and a distortion that linearly transitions from 25 percent to 36 percent over two years $(T=2)$, I have numerically simulated equilibrium time series for various aggregate quantities and displayed them as red curves in Figures $5 b-5 f$ (the other series shown in the Figures are explained below). ${ }^{11}$ The horizontal axis in the Figures is measured in years $t \in[0,7]$. The vertical axis normalizes each series relative to the low-distortion-steady-state values, which are assumed to be the values that prevail before time zero, when it became known the economy would be additionally distorted in the future (with dynamics shown Figure 2 ). Because the aggregate production function is assumed to be Cobb-Douglas (marginal and average products are in fixed proportions), and the time series are shown relative to their low-distortion-steady states, the same series that graphs the marginal product in Figure 5e would also graph the average product.

As noted above, labor is initially high, but Figure $5 \mathrm{~b}$ shows that it is only about one percent above the low-distortion steady state, and even then falls below the lowdistortion steady state within about a month. By the end of the second year, labor has fallen more than 10 percent and consumption (Figure 5c) less than five percent. The marginal and average products of labor have risen three percent (Figure 5d).

\section{B. A Gradual Non-Monotone Transition}

From search frictions to rigid wages to the anticipation of a new-hires credit, a number of potential labor market distortions are likely to be temporary. Others, such as greater political clout for labor unions, new taxes to pay for (and, sometimes, means-tests

\footnotetext{
${ }^{11}$ Appendix II explains the numerical simulation method, as well as the sensitivity of results to assumed parameter values.
} 
associated with the distribution of) growing public pensions and publicly financed health care, may replace some of the temporary distortions, and be present for a number of years after this recession is over. Empirically, the labor distortions (measured as the change in the relationship between consumption, labor productivity, and labor usage) that appeared in the 1930s and in the early 2000s did not fully reverse themselves during the subsequent recoveries. For these reasons, I also consider a gradual emergence of labor market distortions that partially reverses itself before settling a constant value that exceeds that of the pre-existing distortion.

Two kinds of dynamics are possible depending on how much the peak distortion exceeds its long run value. If the peak is not too much above the long run value (i.e., the distortion's time path is sufficiently close to monotonic), then the dynamics are like Figure 2's green curve except that the path in the $[k, c]$ plane approaches the stable manifold of the stationary system with long run distortion level from below. As for the path shown in Figure 2, this path has consumption and capital falling as time $T$ approaches, and there is never a time during which capital is rising from a value below its initial one.

If the distortion's peak is high enough relative to its long run value, capital will drop below its long run value for some time sub-interval of $[0, T]$. In this case, consumption and capital reach their lows before time $T$ and are rising thereafter. ${ }^{12}$ Figure 6 shows a time path for this case in the $[k, c]$ plane.

The contrast between these two possibilities shows how aggregate time series for the first part of the recession can help an observer determine whether labor market distortions are expected to get significantly better. In both cases, the economy reaches a point at which labor rises and the distortion falls. But capital rises and net investment is positive only if labor is anticipated to get significantly higher.

\footnotetext{
${ }^{12}$ The path in the $[k, c]$ plane approaches the stable manifold of the stationary system with long run distortion level from above, and thereby crosses that stable manifold at least twice.
} 


\section{Monthly and Quarterly Indicators of Aggregate Economic Quantities}

The model is especially simple in that time and output each have only two uses: time is used as leisure and consumption and output is used as consumption or investment. The national accounts offer more detail than this, so I aggregate nondefense government consumption, private nondurable consumption, and private service consumption into a single consumption aggregate. Gross domestic private investment, government non defense investment, and private purchases of consumer durables are aggregated together into a single investment expenditure aggregate, and then deflated by the consumption deflator. Labor is measured as the sum of aggregate private work hours (measured as the Aggregate Weekly Hours Index for all Private Industries) and aggregate public work hours (estimated as public sector employment times private work hours per private sector employee).

Investment and GDP are available only quarterly, although real consumer durables expenditure is measured monthly. ${ }^{13}$ The average product of labor is measured as the ratio of GDP to labor usage.

The model is expressed relative to constant exponential trends for population and labor productivity. ${ }^{14}$ I therefore detrend the labor usage data by an assumed expected population growth rate of one percent per year. To match the other measured series with their model counterpart, each is detrended by expected population growth plus $0.6 \%$ : the average annual rate of TFP growth over the four years prior to the recession. ${ }^{15}$

Figures $5 \mathrm{c}-5 \mathrm{e}$ compare the three scenarios from the model to the measured time series for real consumption, the average product of labor, and real investment. For the moment, consider only the scenario represented by the red series in each Figure, which assumes that the labor distortion follows the pattern shown in Figure 4 with $\tau=25 \%, \tau^{\prime}=$ $36 \%$, and $T=2$. In words, the labor distortion stops getting worse in early 2010 , but never gets better. The Figures express model variables a ratio to their values in the

\footnotetext{
${ }^{13}$ Interestingly, detrended consumer durables (which are about a third of overall investment) purchases follow a similar time pattern as overall investment.

${ }^{14}$ For example, $\delta$ in the model is not only capital's rate of economic depreciation, but also the rate at which capital must be augmented to keep up with population and exogenous technical change (for more on growth models with exogenous trends, see Barro and Sala-i-Martin, 2003).

${ }^{15}$ The Hodrik-Prescott filter is often used for this purpose, but the filter sometimes has unusual properties at the very end of a time series - that is, would be more appropriate for 2009 data once some data for 2010 and 2011 are available.
} 
steady state with small distortion $\tau$, and measured variables as a ratio to their value in December 2007 (or, in the case of quarterly data, 2007 Q4).

The model fits the labor data well, although largely by assumption. As in the model, measured real consumption drops the most early in the recession and continues to drop gradually thereafter, although measured consumption does not literally make the instantaneous jump that it does in the model. Investment is somewhat lower in the model than data than in the model, although both fall sharply and hit bottom about 75 or 80 percent of their pre-recession values through about two years. As in the model, measured labor productivity rises during the recession, and is about 4 percent about pre-recession values through about two years.

Given the noticeable quantitative resemblance between the data and such a simple model, it is worth considering what the model suggests about the causes of the recession, and where the economy is headed in the future. The next section calculates the consumption implications of alternative scenarios for the future of the labor distortion, finding that a "partial recovery" scenario fits the consumption data best. It conclude by offering some interpretations of the investment decline that has occurred so far during this recession.

\section{Inferring The Labor Market's Future, and the Magnitude of Investment Distortions, From Current Consumption and Investment Behavior}

The model says that consumption falls the most early in the recession, and that the magnitude of the drop depends on time path for the labor distortion. In other words, consumption is a leading indicator of labor, and could be used with early-recession data to forecast the labor market later in the recession.

Consider first the immediate and permanent labor distortion considered above. Figure 3 showed comparative statics of the ratio of the initial log consumption impact to the initial log labor impact, which was essentially the same as the long run log labor impact. For example, if that ratio were $32 \%$ (as it is for $\eta=1$ and $\sigma=1.35$ ), then the long run log labor impact would be about triple the initial log consumption impact. 


\section{VI.A. Consumption Data Indicates No Near-Term Labor Recovery}

Figure 7 displays the magnitude of the initial log labor impact as a function of the intertemporal consumption substitution elasticity $\sigma$ and the magnitude of the initial log consumption impact. The actual data in Figure 5c shows that detrended consumption fell about 2 percent before the recession was one year old (more below on the current recession's data), so Figure 7 is calibrated with initial consumption impacts of $1 \%, 2 \%$, and 3\%. ${ }^{16}$ As shown in the Figure, the initial labor impact is about $5-6 \%$, and maybe more if $\sigma>1.5$.

Figures 3 and 7 display calculations for the immediate and permanent labor distortion. However, consumption in the model is determined by wealth - the sum of capital and the present value of labor income - regardless of the dynamics of the shock. The immediate impact on the value of capital is zero, so the immediate consumption impact is the impact on the present value of labor income.

When the labor distortion has richer dynamics, such as those considered in Section IV above, there is no single number for "labor impact" because labor varies significantly over time. However, the results in Figure 7 can be interpreted as a weighted average labor impact, in which the weighted average counts the present more heavily according to the present value formula.

Figure $5 \mathrm{~b}$ shows measured labor data, and three different labor paths from the model, with each path based on a different assumed evolution of labor after year two. By construction, all three paths closely follow the data prior to year two. The model paths are labeled "full recovery," "labor permanently 10 percent below trend," and "partial recovery" to reflect the assumed distortion time paths (see Figure 5a).

Figure $5 \mathrm{c}$ shows the measured consumption data, and the three corresponding model paths for consumption. "Full Recovery" implies very little consumption decline (about one percent) through two years because the present value of the labor decline is relatively low. As discussed above, the consumption data seem to suggest that about three times as much labor will be lost in present value than implied by the "full recovery" scenario. The other two paths show a more significant consumption decline. By the

\footnotetext{
${ }^{16}$ The labor elasticity $\eta$ is assumed to be one; Figure 3 showed that results are not sensitive to this parameter.
} 
second year of the recession, both scenarios have real consumption's cumulative decline of two or three percent, and have real consumption falling gradually throughout the year.

Figure $5 \mathrm{~d}$ compares the labor productivity data to the three scenarios from the model. All three scenarios assume the same long run labor productivity and have very similar predictions for labor during the first two years of the recession. Given that all three obtain most of their short run labor productivity variation from variation the amount of labor, it is no surprise that both have similar time paths for labor productivity during the first two years. Labor productivity after year two varies across scenarios largely because labor varies across scenarios. All three scenarios over-predict actual labor productivity in quarters four and five by about a percentage point because total factor productivity did not exactly follow the previous trend.

VI.B. Much, but Not All, of the Investment Decline Appears Efficient Given the Labor Market Distortions

As shown in Figure 5e, all three scenarios predict that real investment would drop sharply, to 75-80 percent of the pre-recession value by the end of the recession's second year. Through the middle of the second year, the data also show real investment about 75 percent of the precession value. Investment declines in the model because capital and labor are complements in production (in the sense that the marginal product of capital increases with the amount of labor), and the labor market becomes increasingly distorted with time.

The scenarios differ from each other, and from the data, in terms of investment during the first year and a half. The "full recovery" scenario fits the investment data the best of the three, and the discussion of labor productivity results (Figure 5d) suggests that this scenario's success with predicting investment may be due to offsetting errors: overpredicting consumption and (in some of the quarters) over-predicting output.

The two scenarios with heavy present value labor losses - "Labor permanently 10 percent below trend" and "partial recovery" - have a short period of somewhat higher investment followed by low investment during the second year. The early investment period reflects model consumers' desire to smooth consumption, in anticipation of low 
output and labor usage in the near future. ${ }^{17}$ The models' investment is quite low early in the second year of the recession, although measured real investment is somewhat lower.

For the last two measured quarters - the middle of 2009 - the data show investment expenditure at $77 \%$ of its 2007 Q4 value (79\% for non-housing investment), whereas the "partial recovery" model shows it at $87 \%$. In this sense, low labor usage explains more than half of the investment decline.

My model has no investment friction, but it indicates how the economy might evolve if the supply of funds for new investment had been curtailed, rather than any labor distortion. Suppose for example that gross investment were frozen at zero for on the time interval $[0, T]$. As of time $T$ the economy would be on the stable manifold of the stationary system shown in Figure 1, with a capital stock less than its steady state value. Prior to that date, labor would be low. Close to time zero, labor would be low due to an income effect: potential output remains high and none of it is spent on investment. Closer to time $T$, capital has fallen do to lack of investment, consumption would have fallen with capital, and labor would be low due to low labor productivity. In summary, the time paths for labor usage and productivity would, for a time, be similar to what they are with the sudden and permanent labor distortion studied in Section III above, but the time path for consumption would be very different.

Moreover, unlike this example, actual gross investment has not been anywhere close to zero, so it remains to be shown how actual investment declines of the magnitude seen in this recession would create large labor usage declines. A credit crisis could also reduce consumption spending, but in this case it is unclear why the labor usage reduction would be of such a great magnitude relative to the spending drop. Figure $5 \mathrm{f}$ displays the ratio of the labor usage decline (as explained above, from a trend line determined by expected population growth) to the real consumption decline (from a trend line determined by expected population and productivity growth) in both the models and the data. Through the recession, the actual fall in labor usage has exceeded the fall in real consumption, and by a wide margin over the last year. The model predicts that labor declines accumulate to soon exceed, and then far surpass, the consumption declines, at

\footnotetext{
${ }^{17}$ The early investment period would be shorter if the intertemporal substitution elasticity $\sigma$ were smaller.
} 
least through the first several years of the recession. The data and my models agree on this general pattern.

Of course, the fact that some of the actual investment decline does not appear efficient given labor usage does not imply that investment frictions explain the rest, because other factors should be considered for a full explanation of actual investment behavior. For example, option value reasoning of Abel et al. (1996) suggests that, to the extent that additional uncertainty about the efficient amount or composition of capital arose in 2008 and 2009, investment might have fallen even if labor had been constant. Investors may anticipate an investment tax credit in 2010, and therefore see investment in 2008 or 2009 as too expensive (Lucas, 1976). Relative prices of investment goods have themselves been high in 2009, although more research is needed to determine whether those high prices are themselves due to capital market frictions.

\section{Conclusions}

A number of events during this recession have shaped the incentives of workers and businesses to earn income, not to mention a number of other factors that have distorted labor markets. Using one of the simplest versions of the neoclassical growth model in which all parameters except the labor distortion are constant, this paper simulates efficient responses to a labor distortion that grew steadily during 2008 and 2009. Assuming that labor distortions only partly reverse themselves over the next couple of years, the model's predictions for consumption and productivity closely match the data so far in this recession.

The model also explains more than half of the actual investment decline as a response to the labor decline. Investment is relatively high in the model for a couple of reasons: (a) consumption adjusts immediately in the model, whereas the actual consumption drop of 2008 took several months, and (b) actual productivity did grow during in late 2008 and early 2009, but slightly below the trend assumed in the model. Since investment is a small fraction of total spending, these small deviations between 
model and data consumption and output create larger deviations between model and data investment.

Figures $8 \mathrm{a}-8 \mathrm{c}$ reproduce the "partial recovery" scenario results in levels, and thus serve as predictions for national accounts data between now and 2014. Figure $5 \mathrm{~b}$ already showed that labor usage per capita will not return to pre-recession levels at any time between now and 2014. Figure 8a suggests that the aggregate hours index (private and public sectors combined) will not decline much more than it had through October 2009, but will not return to pre-recession levels until sometime in 2012. As shown in Figure $8 \mathrm{~b}$, real consumption expenditure is already slightly above pre-recession levels, and is expected to rise further hereafter. However, as shown in Figure 2, the average annual rate of increase from now until the end of 2014 (1.3 percent) is expected to be less than the sum of population and total factor productivity growth (assumed to be 1.6 percent). Real GDP has probably hit its lows, and Figure 8c shows that its growth rate over 201011 is expected to be 2.0 percent per year: somewhat more than the sum of population and total factor productivity growth. Thus, real GDP will grow significantly over the several years, but the recovery will be "jobless" in the sense that employment and hours per capita will not return to pre-recession levels for many years, and investment-driven in the sense that real GDP will grow faster than consumption until 2012.

In order to illustrate the explanatory power of the labor distortion, I assume that all other fundamentals stayed exactly on trend during this period (and will continue to do so) and have assumed highly stylized dynamics for the labor distortions. Reasonable people can debate whether these assumptions are approximately accurate, but certainly they are not literally true, ${ }^{18}$ and therefore even if the forecasts offered in my Figures 5 and 8 are reasonably accurate, they are not the best forecasts possible given current information. For example, total factor productivity growth was somewhat low prior to the recession, so as of 2008 one might have reasonably expected total factor productivity growth to be somewhat low at first, and then increase a bit with time. Nor is it literally true that all post-2007 changes in the "labor distortion" (or labor market specification

\footnotetext{
${ }^{18}$ Chari, Kehoe, and McGrattan (2007) offer a methodology (not yet applied to this recession) which would account for all of the changes during a recession to one of several shocks in the neoclassical growth model. Because their method includes the same labor market condition (7) as mine, and the same definition of total factor productivity, we would agree that changes in the labor distortion during this recession were substantial and TFP changes minor.
} 
error) were unanticipated, because among other things, it was known that the baby boom was approaching retirement, which would shift aggregate labor supply by itself, not to mention the distortionary effects that might follow as public policies levy additional taxes to support the additional retirees. But, if this paper's emphasis on new and significant labor market distortions is correct, these various other omitted factors will tend to negligible at least in the near term.

This recession has been unusual in that so much of it can be "explained" with a large increase in the labor distortion, and little deviation of productivity from trend. Figure 9 shows data from this recession, and two others. Each series corresponds to a recession, beginning with the last quarter of the prior expansion, and following the data quarterly until eight quarters after the beginning of the recession (or, in the case of 20089, the seven quarters for which data is available). The horizontal axis measures the "labor productivity shift" - the change in real GDP per unit labor usage that is beyond what would occur due to a movement of the marginal productivity of labor schedule (assuming a labor share of 0.7 ). For example, a labor productivity shift of zero means that the real GDP change since the end of the prior expansion was equal to $70 \%$ of the labor usage change. The vertical axis measures the labor distortion change that makes the change in the labor market condition (7) hold with equality. ${ }^{19}$

The 1980s recession had little change in the labor distortion early in the recession, but had labor productivity fall significantly. This type of recession was common enough that the real business cycle literature (such as the classic Kydland and Prescott, 1982) attempted to explain business cycles only with productivity shocks. The 2001 recession had a significant increase in the labor distortion, but also a remarkable outward shift in labor productivity. The current recession is unusual that productivity shifted only slightly (roughly consistent with its prior trends) but the labor distortion increased by several percentage points.

\footnotetext{
${ }^{19}$ These calculations are the same as in Mulligan (2009a, Figure 14) except that the marginal rate of substitution function is taken to coincide with equation (5) from the current paper (this makes little difference in the empirical results). Mulligan (2009a) examines two additional postwar, plus the Great Depression of the 1930s.
} 


\section{Appendix I: Proof of Lemma}

Lemma If $\sigma \in\left(0,(1-\alpha)^{-1}\right)$, the elasticity of labor with respect to capital is less than the elasticity of consumption with respect to capital along the stable manifold of the stationary system.

Proof From the labor market condition (7) the elasticity of labor with respect to $k$ along the stable manifold satisfies:

$$
\begin{aligned}
& ((1-\alpha) \eta+1)(\ln n(k)-\ln k)=\eta \ln \left(\frac{1-\tau}{\gamma} \alpha A\right)-\frac{\eta}{\sigma} \ln c(k)-\ln k \\
& ((1-\alpha) \eta+1)\left(1-\frac{d \ln n(k)}{d \ln k}\right)=\frac{\eta}{\sigma} \varepsilon(k)+1 \\
& \varepsilon(k)-\frac{d \ln n(k)}{d \ln k}=\frac{\frac{\eta}{\sigma} \varepsilon(k)+1}{(1-\alpha) \eta+1}+\varepsilon(k)-1=\frac{\frac{\eta}{\sigma}+(1-\alpha) \eta+1}{(1-\alpha) \eta+1} \varepsilon(k)-\frac{(1-\alpha) \eta}{(1-\alpha) \eta+1}
\end{aligned}
$$

The consumption elasticity exceeds the labor elasticity if and only if:

$$
\varepsilon(k)>\frac{(1-\alpha) \eta}{\frac{\eta}{\sigma}+(1-\alpha) \eta+1}
$$

To confirm that this is satisfied for $k>k_{s s}$ (the reader can confirm that the proof for $k<k_{s s}$ is quite similar), note that Proposition 1 implies: 


$$
\begin{aligned}
& \frac{c}{k}+\delta<\frac{\delta+\rho}{1-\alpha}<\frac{\delta+\rho}{1-\alpha}+\frac{\sigma}{(1-\alpha) \eta}[1+(1-\alpha) \eta]\left[\delta+\rho-(1-\alpha) A N^{\alpha}\right] \\
& (1-\alpha) \eta\left(\frac{c}{k}+\delta\right)<(\delta+\rho) \eta+\sigma[1+(1-\alpha) \eta]\left[\delta+\rho-(1-\alpha) A N^{\alpha}\right] \\
& (1-\alpha) \eta\left(\frac{c}{k}+\delta-(1-\alpha) A N^{\alpha}\right)<(\delta+\rho) \eta+\sigma[1+(1-\alpha) \eta]\left[\delta+\rho-(1-\alpha) A N^{\alpha}\right]-(1-\alpha) \eta A N^{\alpha} \\
& (1-\alpha) \eta\left(\frac{c}{k}+\delta-(1-\alpha) A N^{\alpha}\right)<\left[\delta+\rho-(1-\alpha) A N^{\alpha}\right] \eta+\sigma[1+(1-\alpha) \eta]\left[\delta+\rho-(1-\alpha) A N^{\alpha}\right] \\
& \frac{(1-\alpha) \eta}{\eta+\sigma[1+(1-\alpha) \eta]}<\frac{\delta+\rho-(1-\alpha) A N^{\alpha}}{\frac{c}{k}+\delta-(1-\alpha) A N^{\alpha}} \\
& \varepsilon(k)=\sigma \frac{\delta+\rho-(1-\alpha) A N^{\alpha}}{c}>\frac{(1-\alpha) \eta}{\eta / \sigma+1+(1-\alpha) \eta} \\
& \frac{\delta}{k}+\delta-(1-\alpha) A N^{\alpha}
\end{aligned}
$$

where the final equality is the elasticity of the stable manifold in the $[k, c]$ plane, calculated from equation (11). 


\section{Appendix II: Calibration and Simulation}

The model has five parameters to be calibrated: labor's share $\alpha$, the adjusted depreciation rate $\delta$, the adjusted time preference rate $\rho$, and wage elasticity of labor supply $\eta$, and the consumption elasticity $\sigma$. Labor's share is taken as 0.7 , in order to coincide with measured values of the share of employee compensation in nonproprietor's private national income. ${ }^{20}$

The adjusted depreciation rate is taken as a pure depreciation rate minus population growth minus (TFP growth)/ $\alpha$ : the rate of gross investment expenditure on a balanced growth path. TFP growth (specifically, real GDP growth adjusted for hours of labor usage and real non-residential private fixed assets) varied considerably prior to the recession: it averaged $0.0 \% / \mathrm{yr}$ in 2006 and 2007, 0.1\%/yr in 2005-7, 0.4\%/yr 2004-7, and $1.3 \% / y r$ 2003-7 (which was also close to its average over longer periods). I use the value of $0.4 \%$ per year to reflect the likely possibility that, by 2008 , TFP growth was expected to be positive, but less that it has been in the 1990s and early 2000s. I also consider alternate values of $0.0 \% / \mathrm{yr}$ and $1.0 \% / \mathrm{yr}$.

Population growth is taken as 1.0 percent per year. The annual pure depreciation rate is taken as $5.5 \%$ plus $0.5 \%$, where the $5.5 \%$ is the ratio of private fixed asset depreciation per dollar of real private fixed assets in the national accounts. The model's investment is produced with the same technology as consumption goods, so it is best interpreted as investment expenditure deflated with the consumption deflator, and as such is expected to "depreciate" an additional amount according to the expected rate of decline of the real price of investment goods, which I take to be $0.5 \%$ per year. The benchmark adjusted depreciation rate is therefore $7.6 \% / \mathrm{yr}$, with alternative values of $7.0 \% / \mathrm{yr}$ and $8.4 \% / \mathrm{yr}$ depending on the alternative assumed value for expected TFP growth.

The "consumption elasticity" is more precisely the elasticity of consumption growth with respect to the marginal product of capital. Some of the macroeconomics and consumption literature has assumed that this elasticity is necessarily the same as the elasticity of consumption growth with respect to the real return on safe short term loans, which in some models is closely related to the marginal product of capital. However, the

\footnotetext{
${ }^{20}$ Capital and labor income and not separately measured for proprietors, or in the public sector.
} 
asset pricing literature has shown that the marginal product of capital and the risk free interest rate are often change quite differently, so I stick with the more literal interpretation. Mulligan (2004) finds an elasticity of consumption growth with respect to the (after-tax) marginal product of capital to be about 1.35. This paper also reports sensitivity analysis using values of $\sigma=0.7$ and $\sigma=2.0$.

The model's steady state ratio of consumption to output is $(\alpha \delta+\rho) /(\delta+\rho)$. I choose the rate of adjusted rate of time preference $\rho$ so that the consumption output ratio is 73 percent as in the data. This implies that the benchmark $\rho$ is $1.0 \% / \mathrm{yr}$, with alternative values of $0.9 \% / \mathrm{yr}$ and $1.1 \% / \mathrm{yr}$ depending on the alternative assumed value for expected TFP growth.

If values for the labor distortions in the price dimension (such as rates of income taxation at each point in time) were taken as given, and one were to simulate how labor would respond, then of course the Frisch labor supply elasticity $\eta$ would be a critical parameter. However, I have not directly estimated the labor distortion rates but rather assume that they are large enough to explain most of what has happened in labor usage so far in this recession. In this sense, the labor supply elasticity does not matter for my purposes, because a smaller labor elasticity can always be reconciled with the data by assuming larger values for the distortion.

My benchmark value for the labor elasticity is one. With this value, a two year increase of the labor distortion by about 10 percentage points explains much of the labor decline over the first two years of the recession (see Figures $5 \mathrm{a}$ and $5 \mathrm{~b}$ ). If the labor elasticity were assumed instead to be, say, 0.5 , then the same labor dynamics could be explained, but with a labor distortion that increases by about 20 percentage points instead of 10. The red and green series in Figure 10a illustrate this point. The red series is simulated for the baseline parameters (all series assume a "partial recovery" scenario for distortions), and the green series is for elasticities $\eta$ and $\sigma$ assumed to be half of their baseline values. Both follow very similar paths through 2009 because the baseline parameters are simulated with distortion dynamics that are about half those simulated for the green series. 
The smaller elasticities are consistent with a somewhat better recovery (Figures 10a-c) because more of the 2008 consumption drop can be inferred as consumption smoothing rather than expectations of relative heavy distortions in the distant future.

Figures 10b-c show that results are more sensitive to assumptions about TFP growth. The blue series are based on an assumed 1.6\% annualize TFP growth rate, as compared to zero for the black series and $0.6 \%$ for the baseline. Greater TFP growth is consistent with greater labor distortions in the future because the 2008 consumption seems especially large when compared against TFP and population growth. Ultimately, higher TFP growth means more consumption and real GDP growth.

Time paths were simulated in three steps. First, the stable manifold for the stationary system having the smaller (long run) distortion was calculated by numerically solving the ordinary differential equation in $k$ (11) evaluated at the smaller (long run) distortion, respectively, using the steady state as the boundary condition. Second, I guessed a time $T$ point on the stable manifold for the stationary system having the long run distortion and numerically solved the dynamical system (1) and (6), which is nonstationary because the labor distortion varies with time, backwards in time until the capital stock $k$ corresponded to the initial steady state capital stock. ${ }^{21}$ I then checked whether $T$ units of time have evolved and, if not, repeated the procedure after taking as my guess another point on the stable manifold for the stationary system having the long run distortion. Third, dynamics in the time dimension after time $T$ were simulated by numerically integrating the capital accumulation equation (1), imposing that consumption be on the stable manifold for the stationary system having the long run distortion.

\footnotetext{
${ }^{21}$ Time $T$ is the calendar time when the labor distortion stops changing.
} 
Table 1. Parameter Values Assumed for the Purposes of Numerical Results

\section{Parameter}

$\alpha$ labor's share

$\rho$ time preference rate, adjusted

$\delta \quad$ capital depreciation rate, adjusted

$\sigma$ intertemporal consumption elasticity

$\eta$ labor substitution elasticity

$A$ productivity level

$\gamma$ leisure preference

\section{Value(s) Units Comments}

0.7 share

$1.4 \%$ per year chosen to produce a steady-state investment consumption ratio of 0.34

7.6\% per year $5.5 \%$ pure depreciation, adjusted for $1 \%$ populaton growth and $0.6 \%$ technical change, and 0.5 percent expected investment price trend

$[0.5,2]$ elasticity benchmark value of 1.35 (Mulligan, 2005)

$[0.5,2]$ elasticity benchmark value of 1

normalized normalized so that the low-distortion steady state capital and normalized labor are one 
Fig 1. Capital-Consumption Phase Diagram for the Stationary System

The Figure shows the stationary system's steady state, dynamics, and stable manifold.

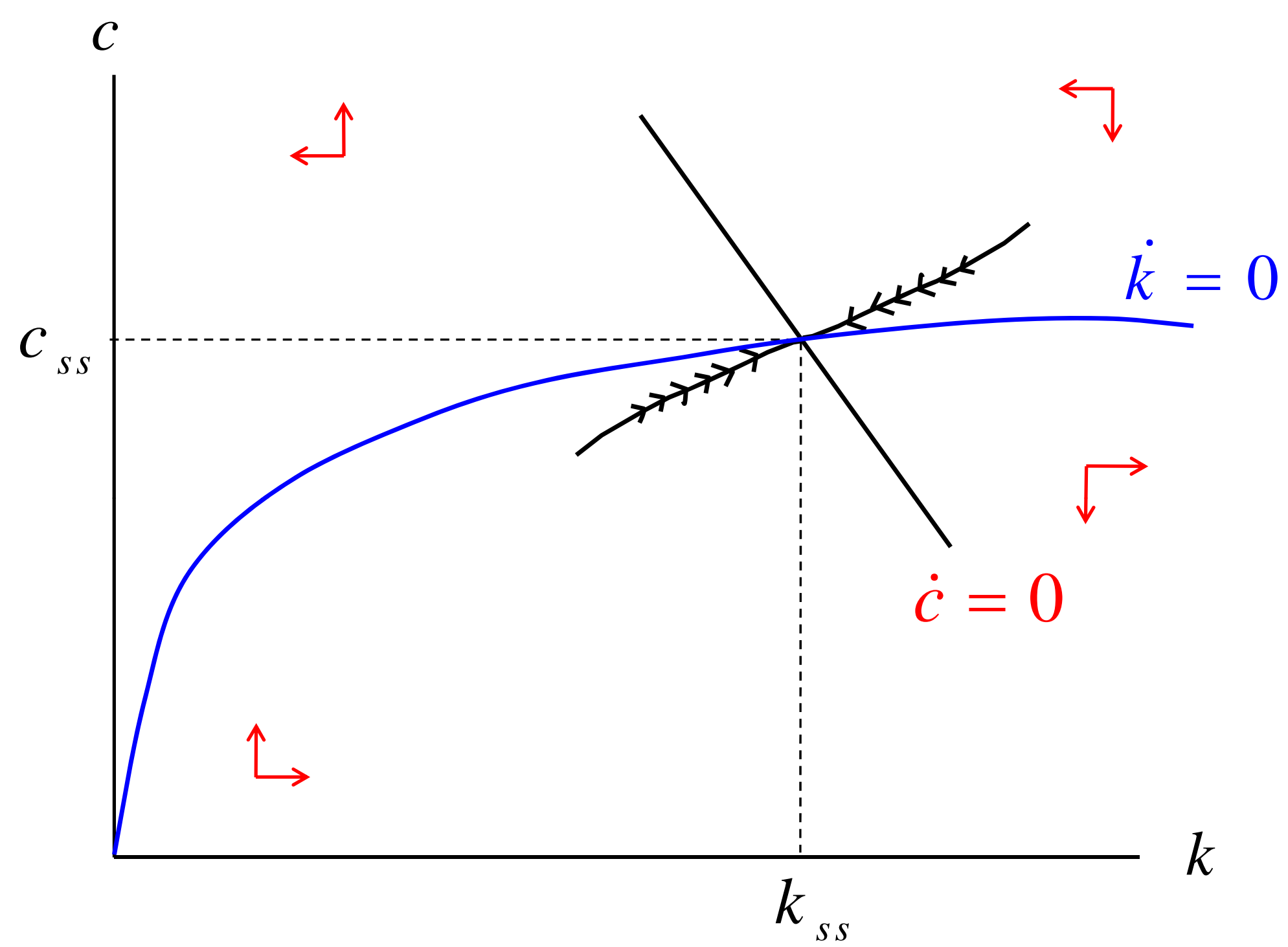




\section{Fig 2. Stable Manifolds for High and Low Distortions}

The Figure shows the system's dynamics and stable manifold. The dynamics shown by the red arrows correspond to the "low" labor market distortion that prevailed before date 0 . When the new distortion path is first anticipated at date 0 , consumption falls, but not as far as it will fall in the long run. The new stable manifold (shown as a black path) describes dynamics once the distortion has reached its higher long run value.

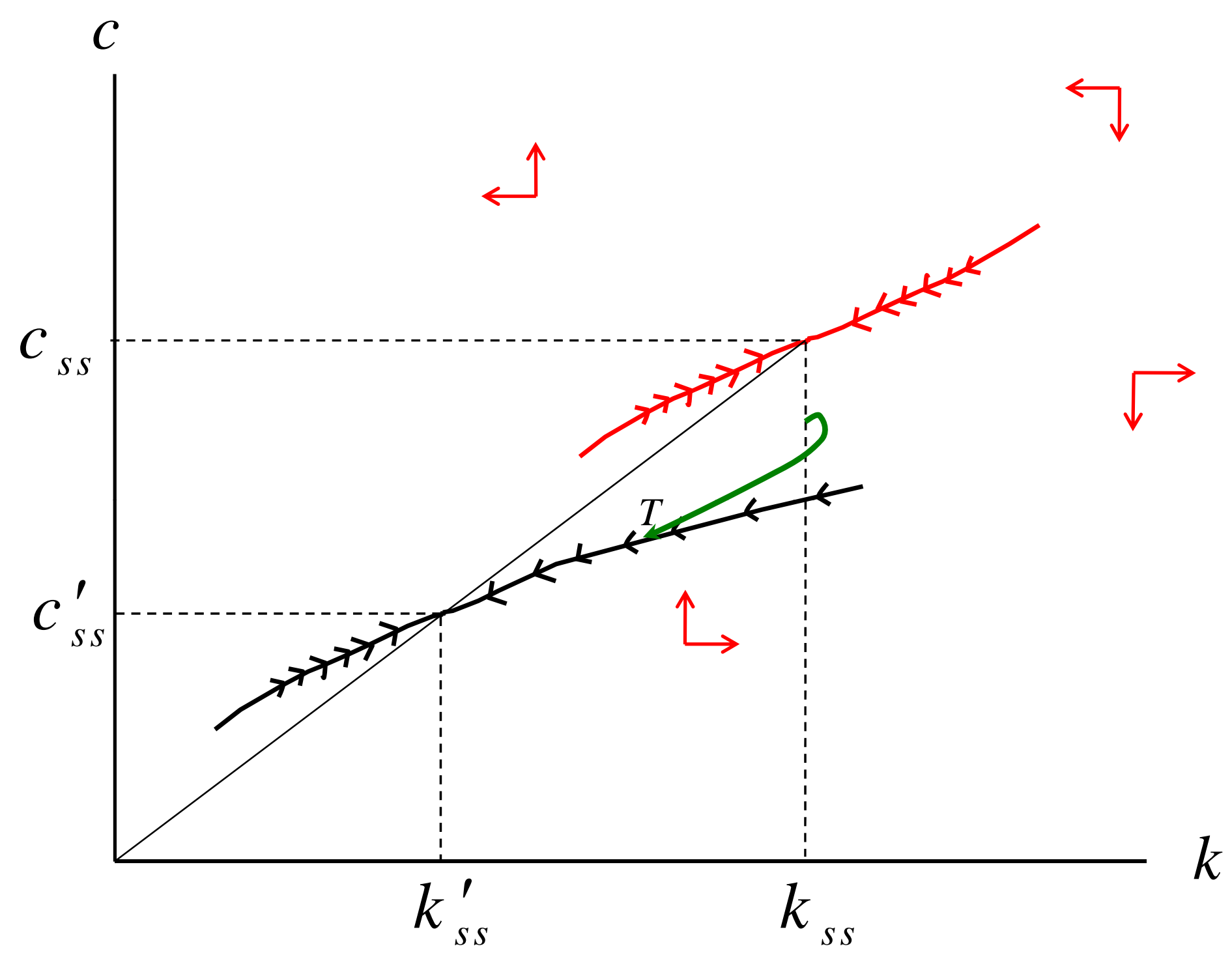


Figure 3: Initial Log Consumption Impact of a Permanent Labor Distortion

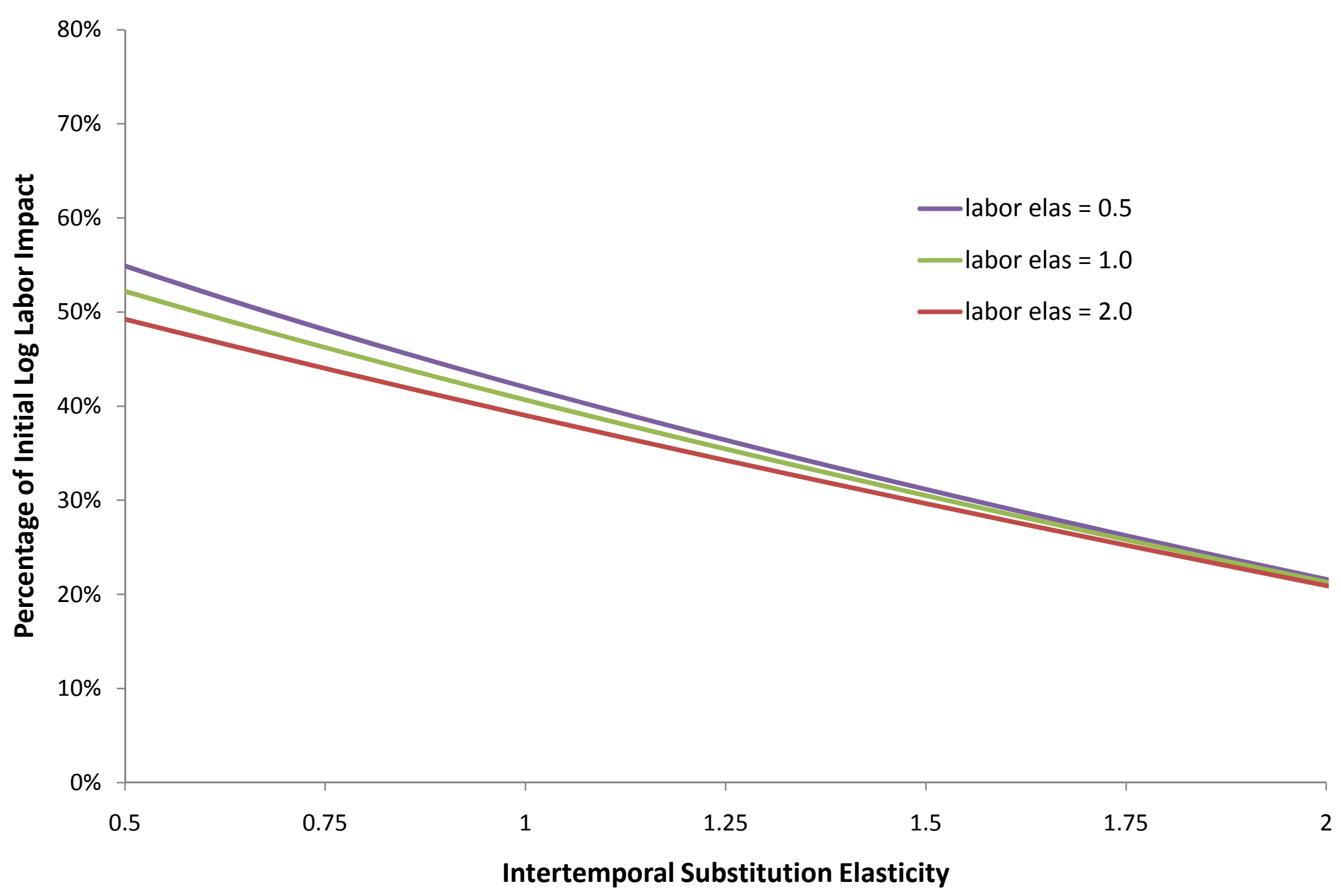


Fig 4. Time Path for the Gradually Emerging Labor Market Distortion

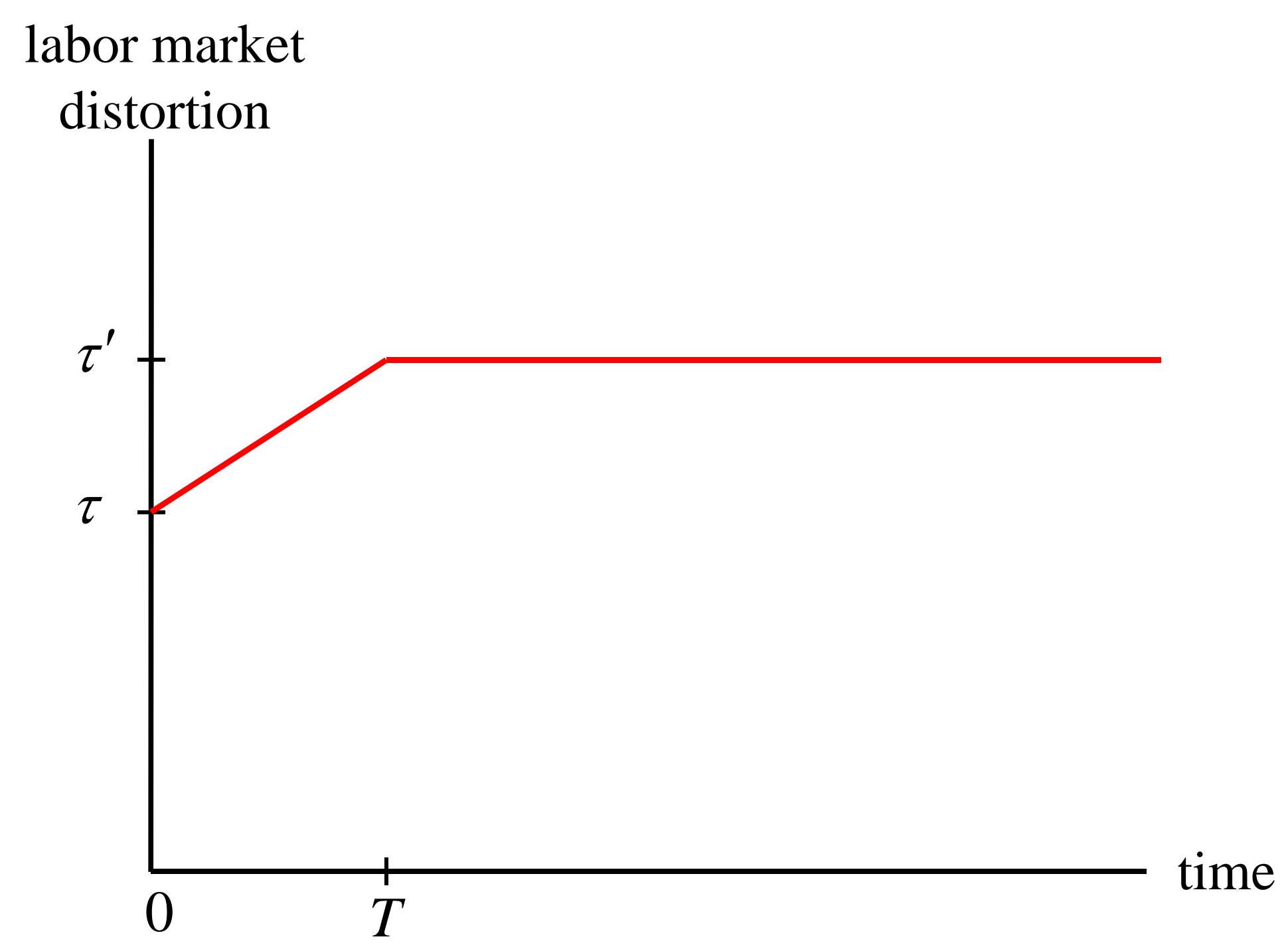




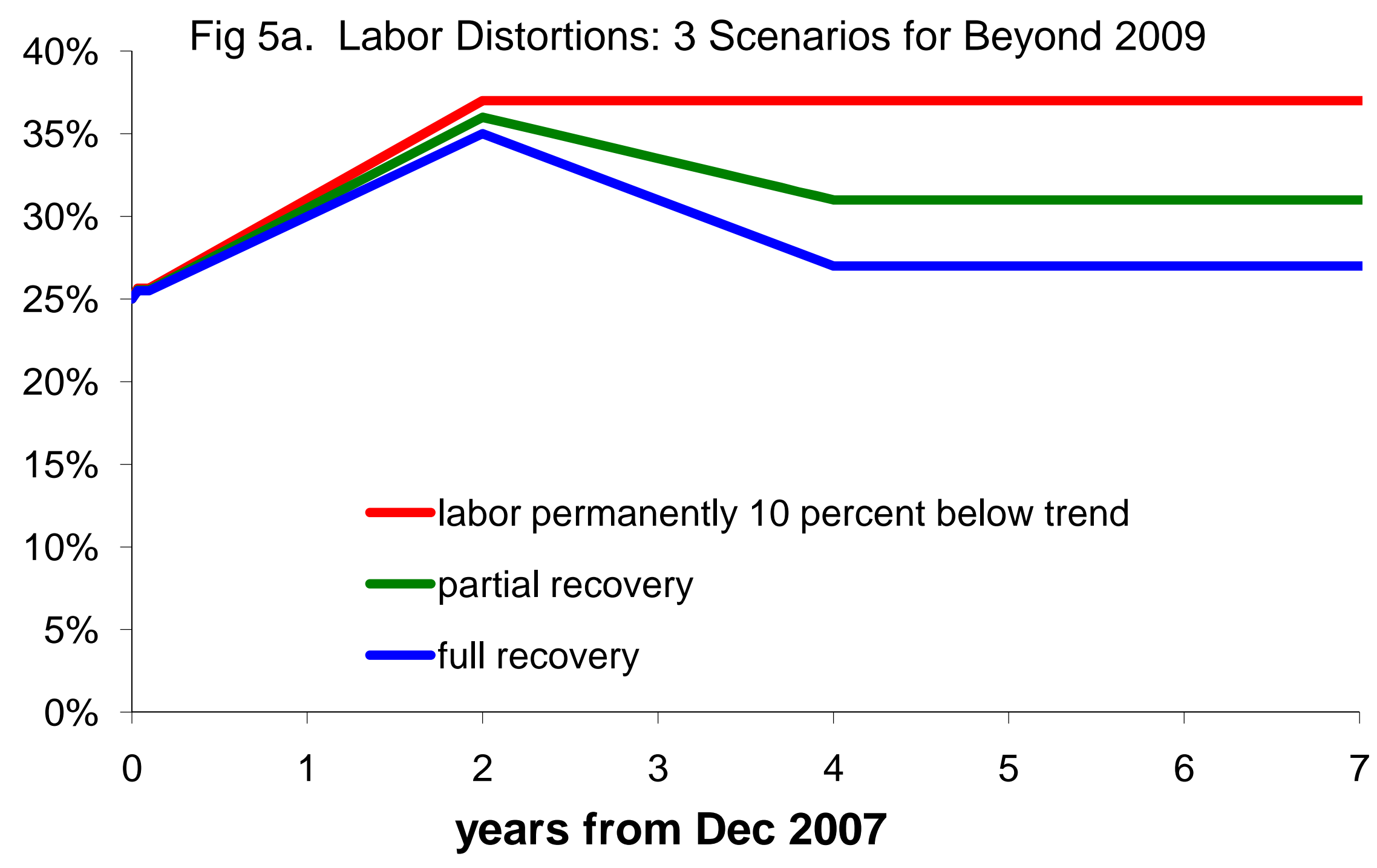


Fig 5b. Labor Usage: Data \& 3 Scenarios for Beyond 2009

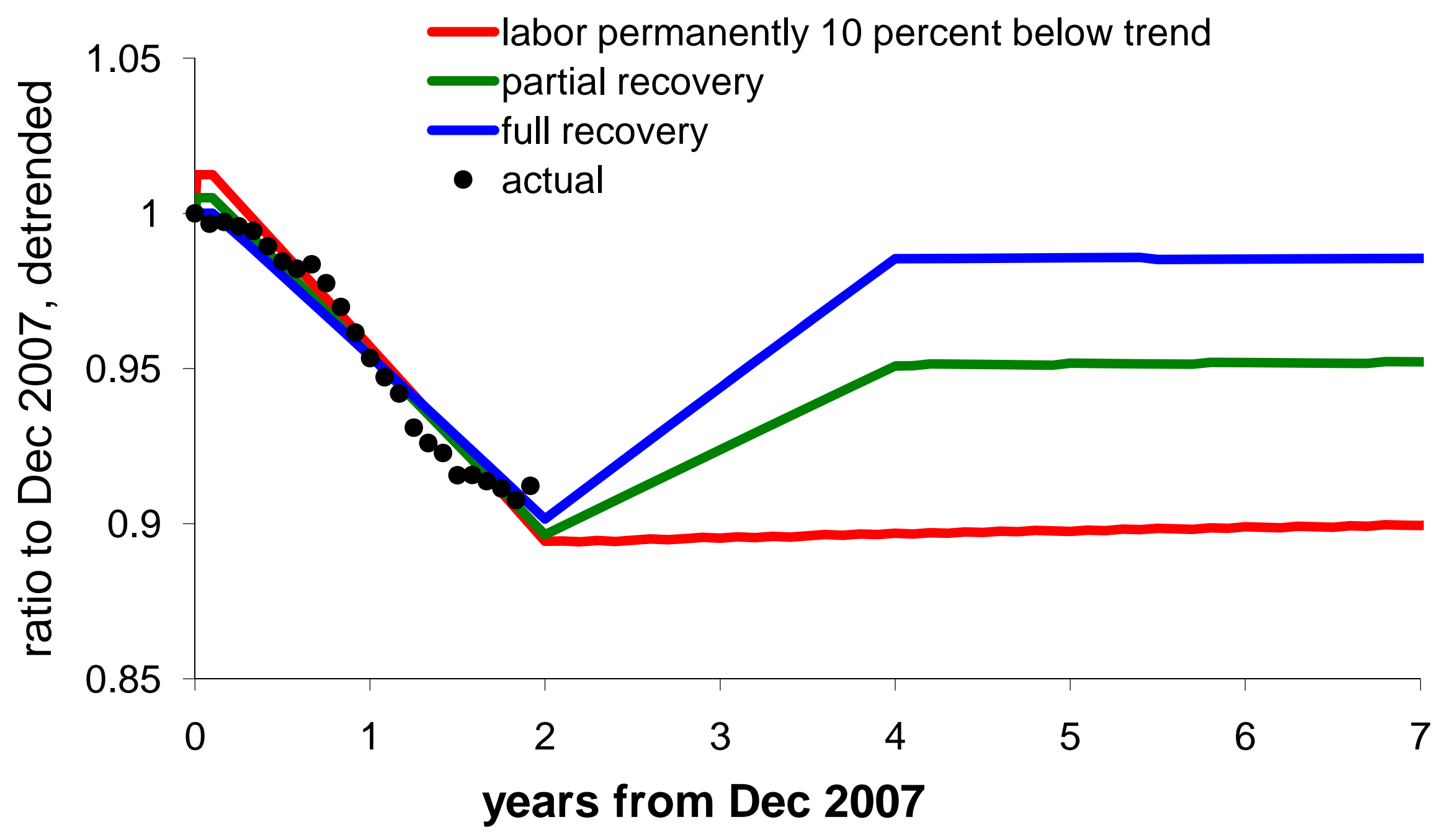


Fig 5c. Consumption: Data \& 3 Scenarios for Beyond 2009

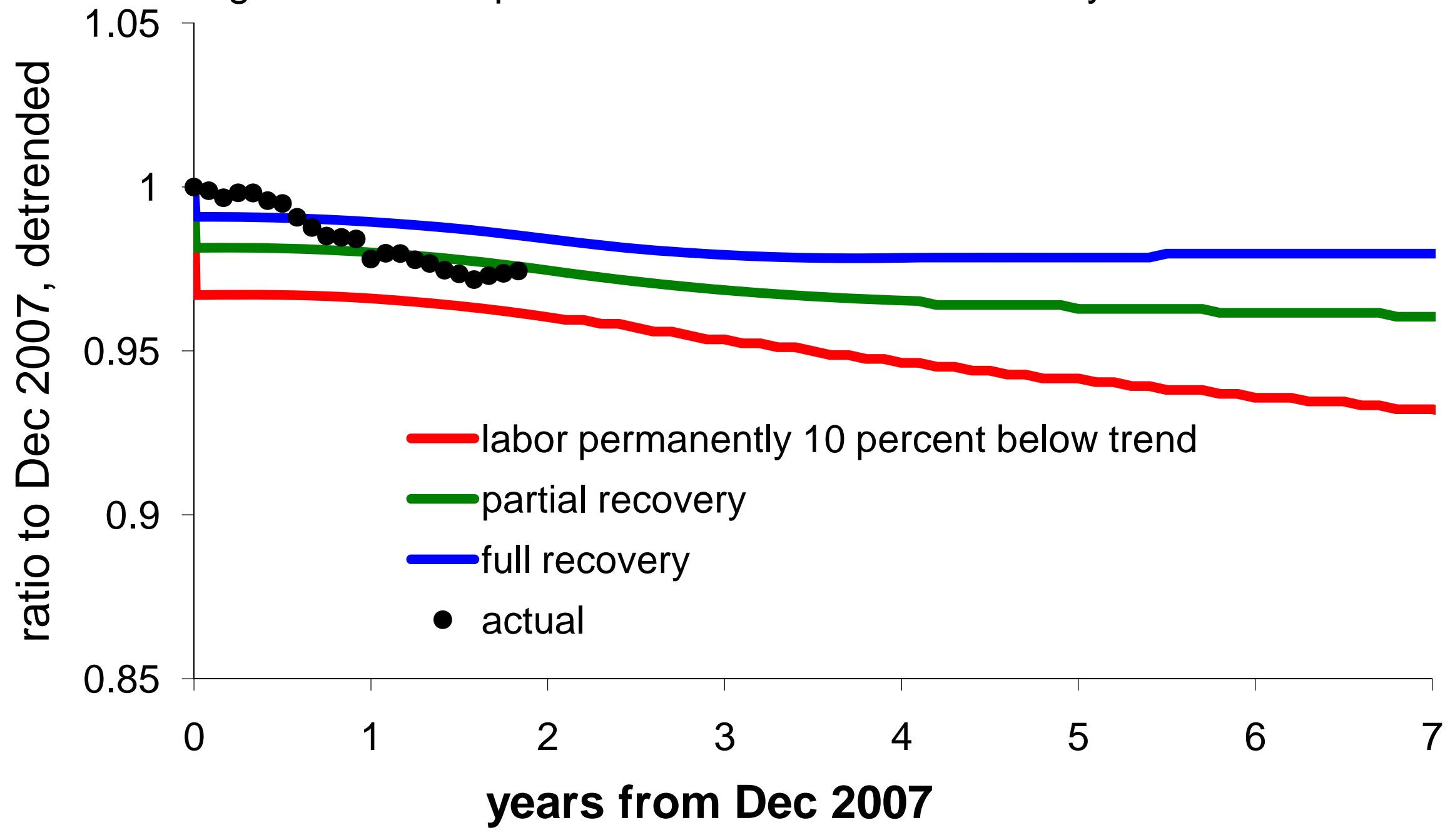


Fig 5d. Labor Productivity: Data \& 3 Scenarios for Beyond 2009

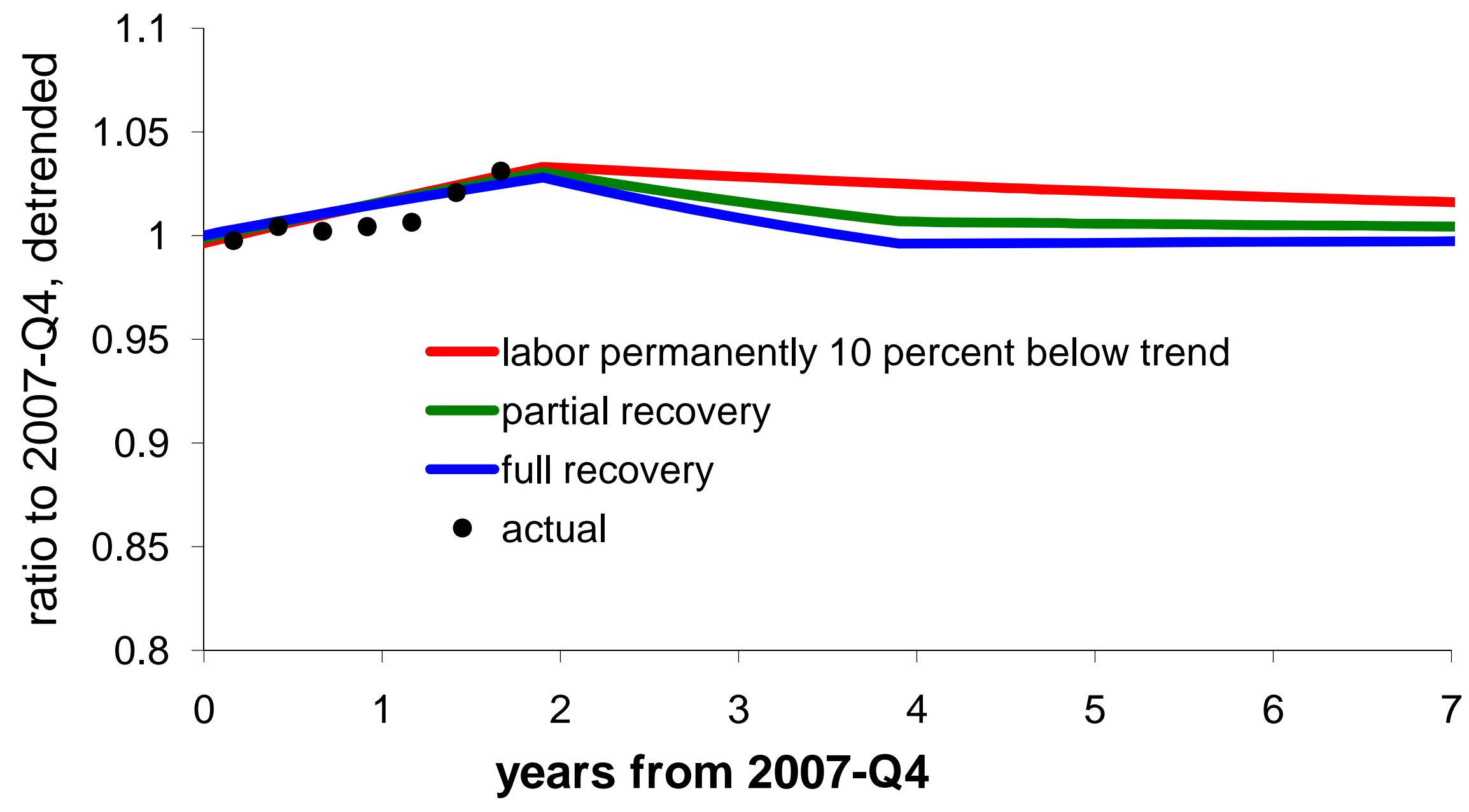


Fig 5e. Investment: Data \& 3 Scenarios for Beyond 2009

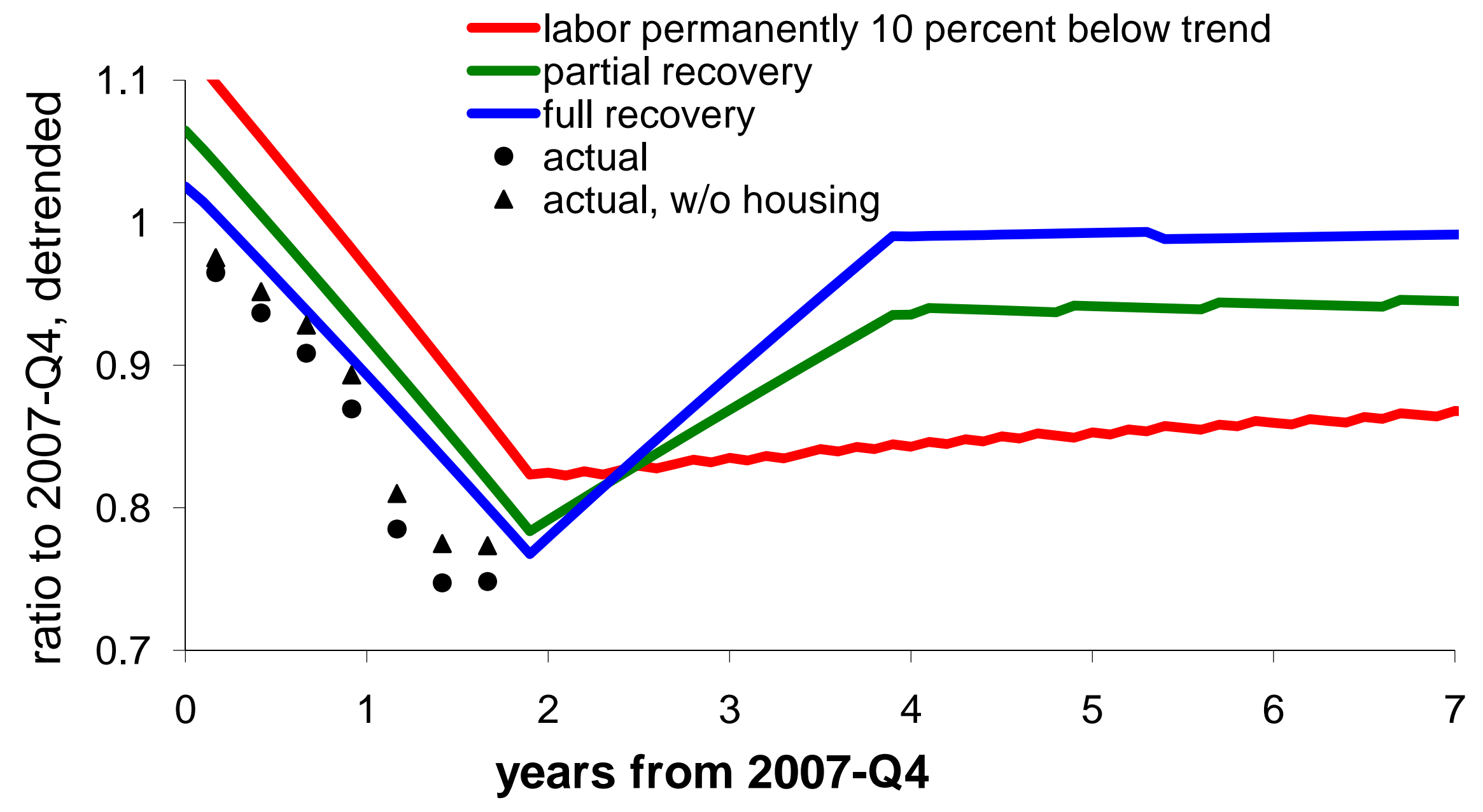


Fig 5f. Relative Impact: Data \& 3 Scenarios for Beyond 2009

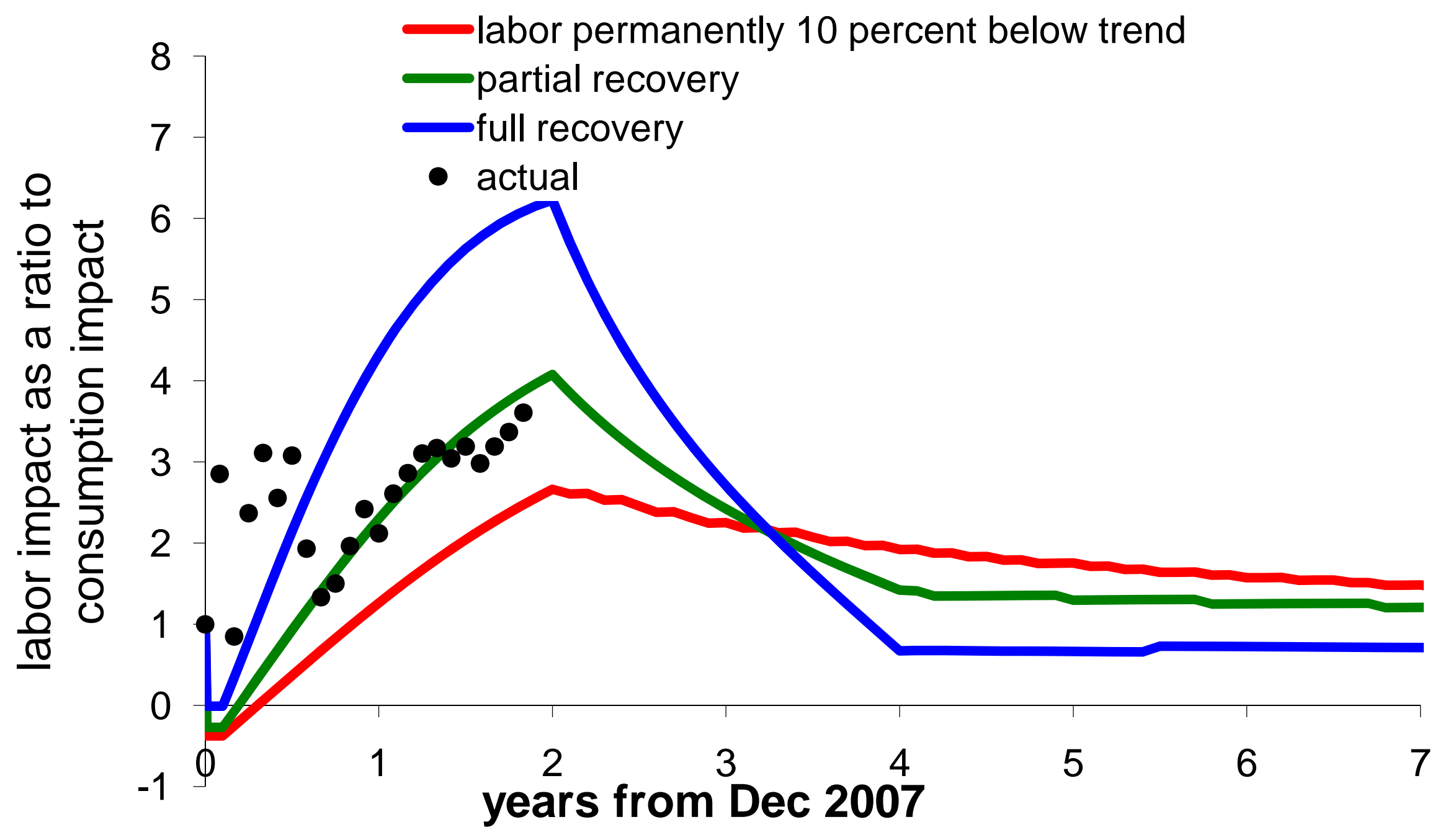




\section{Fig 6. Dynamics when the High Distortion is Largely Temporary}

The Figure shows the system's dynamics and stable manifold. The dynamics shown by the red arrows correspond to the "low" labor market distortion that prevailed before date 0 . When the new distortion path is first anticipated at date 0 , consumption falls, but not as far as it will fall in the long run. The new stable manifold (shown as a black path) describes dynamics once the distortion has reached its higher long run value.

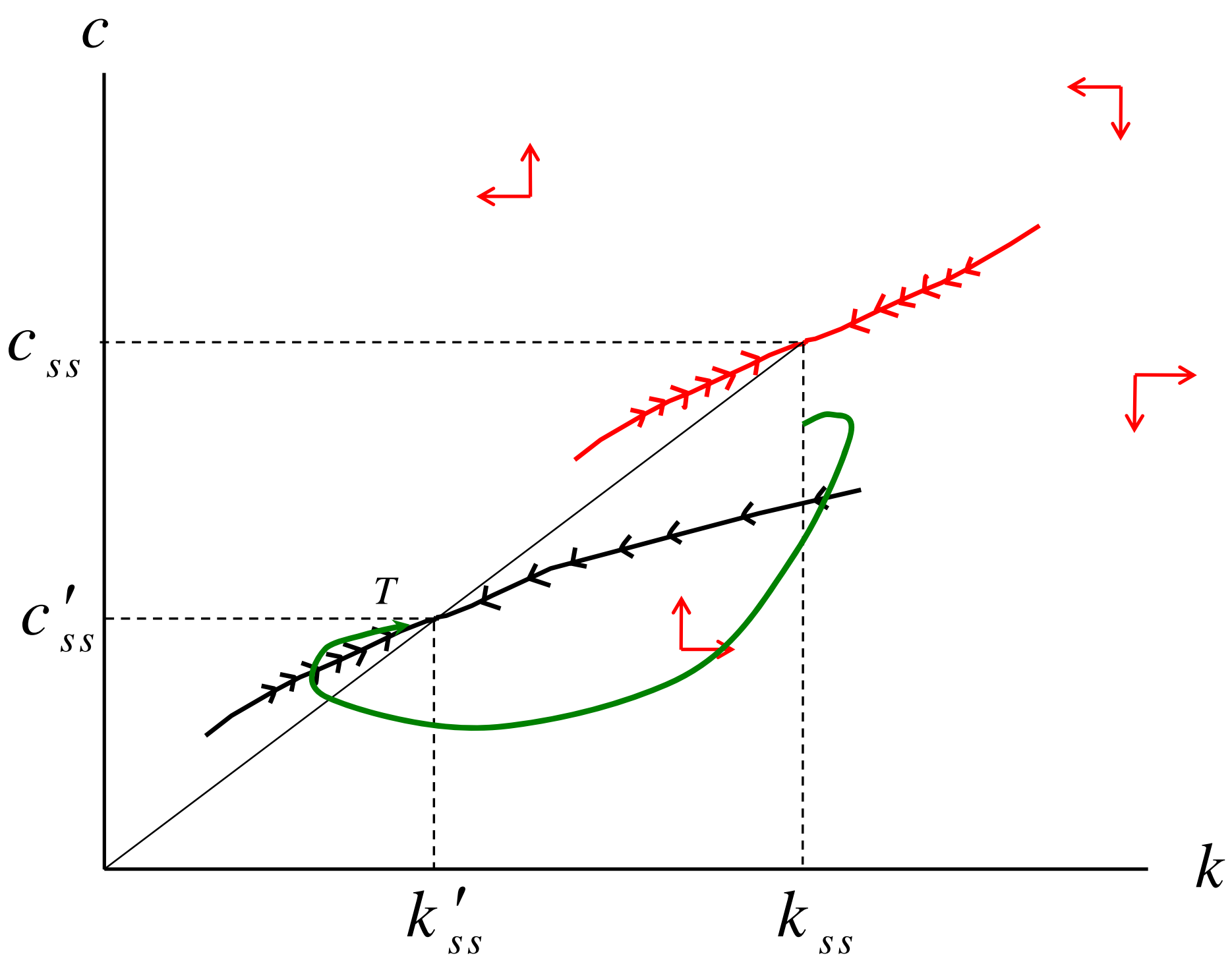


Figure 7: Inferring Average Labor Impact from the Initial Consumption Impact

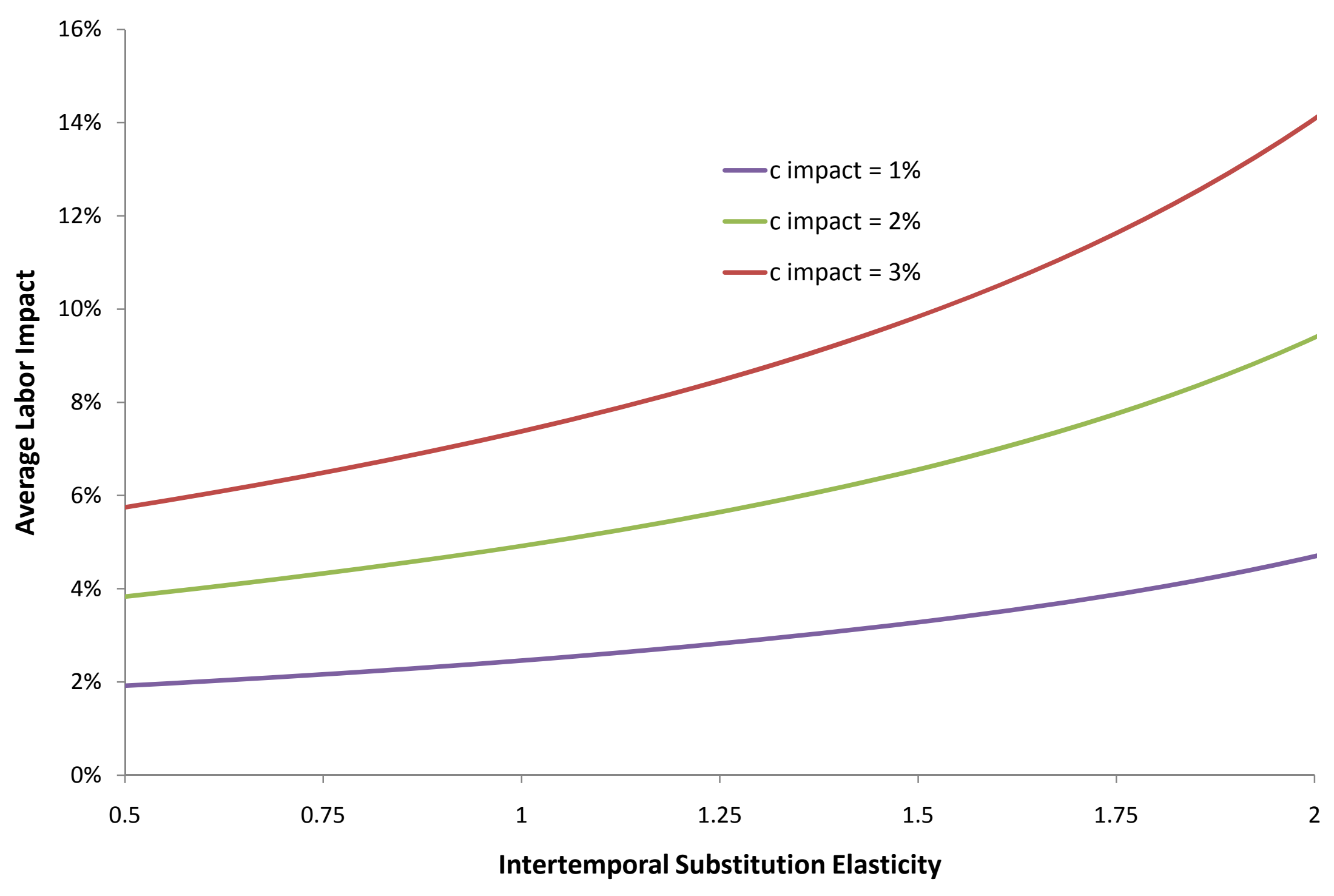


Fig Ba. Labor Usage: Data vs Partial Recovery Scenario

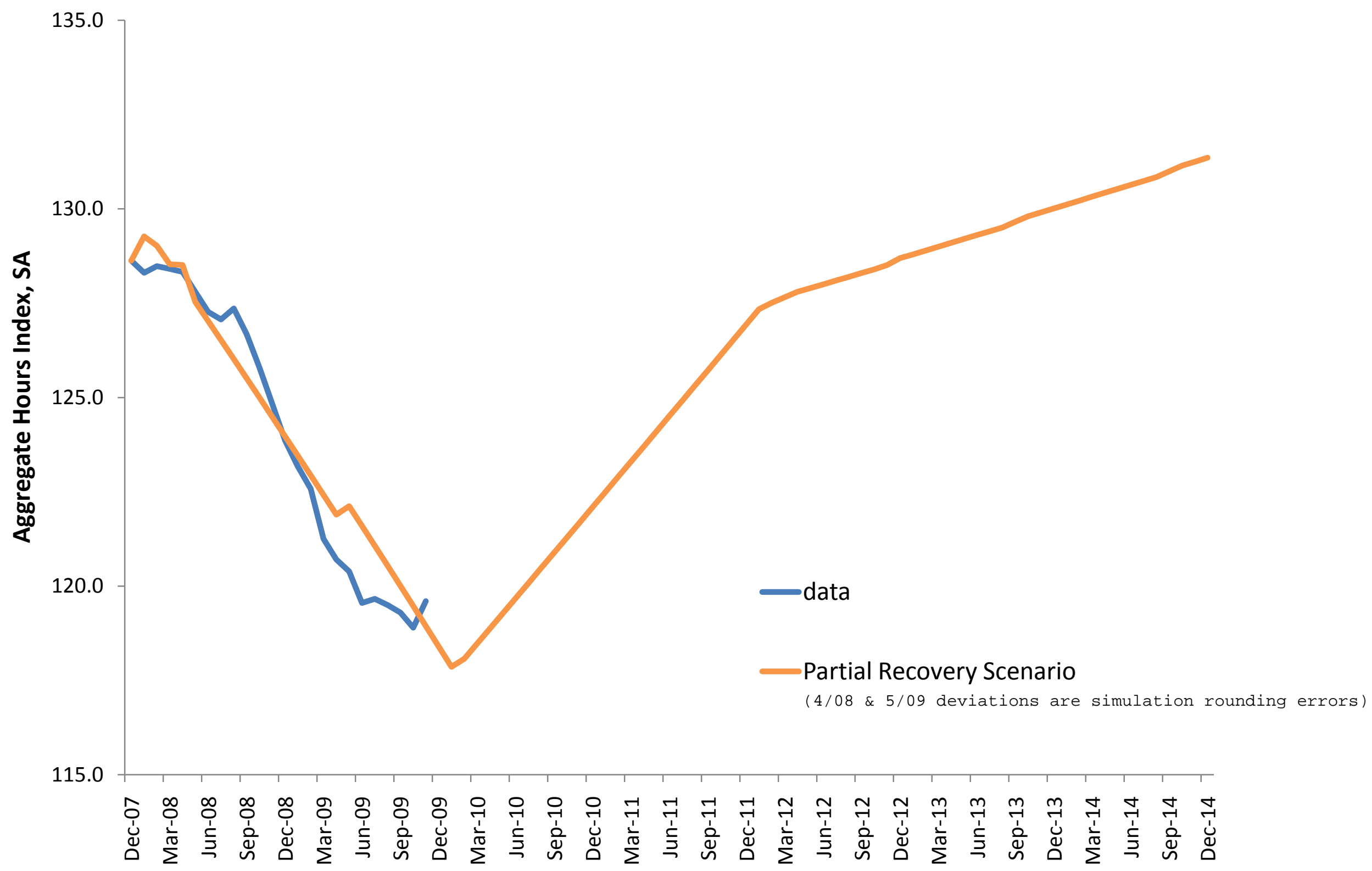


Fig 8b. Real Consumption: Data vs Partial Recovery Scenario

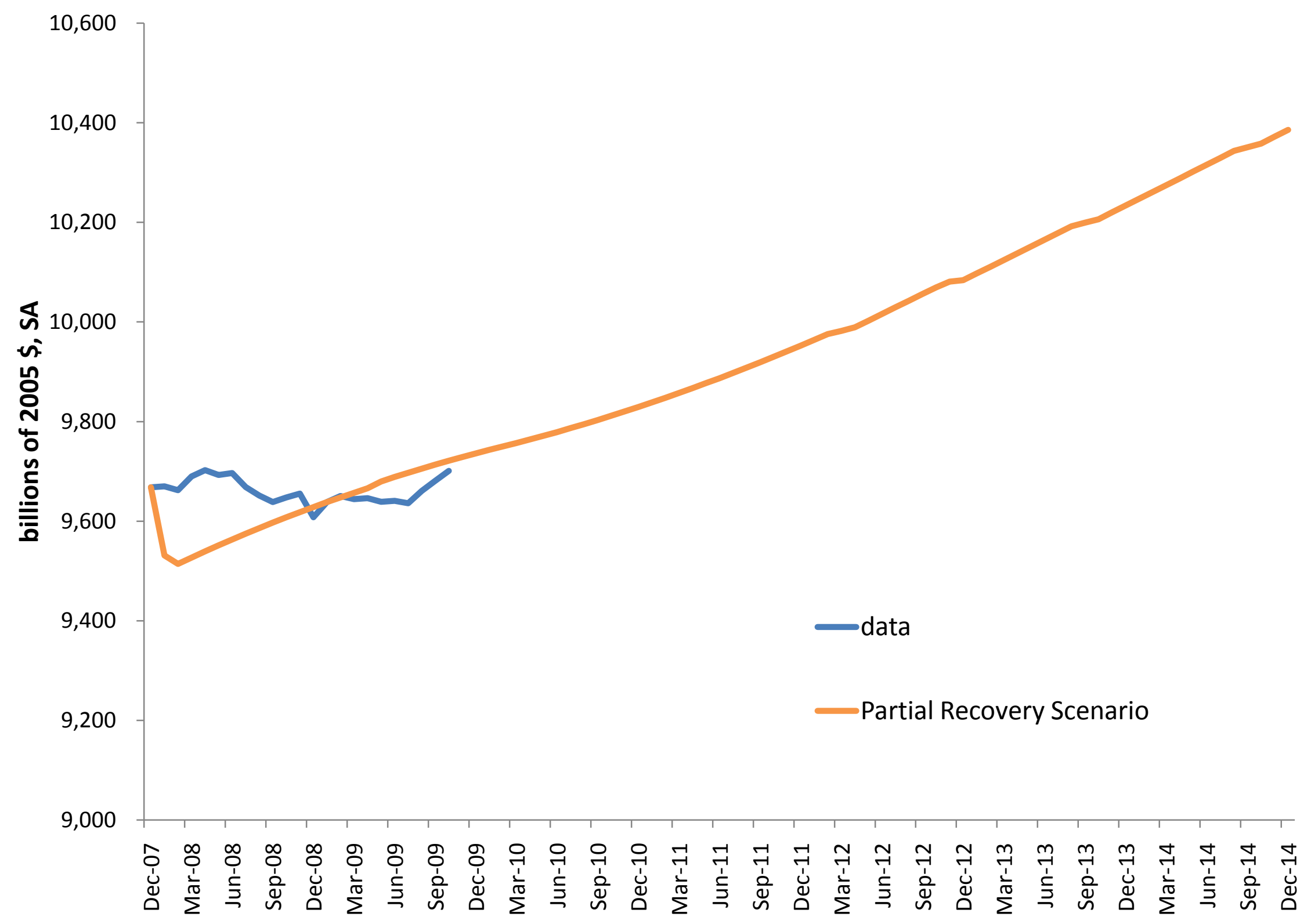


Fig 8c. Real GDP: Data vs Partial Recovery Scenario

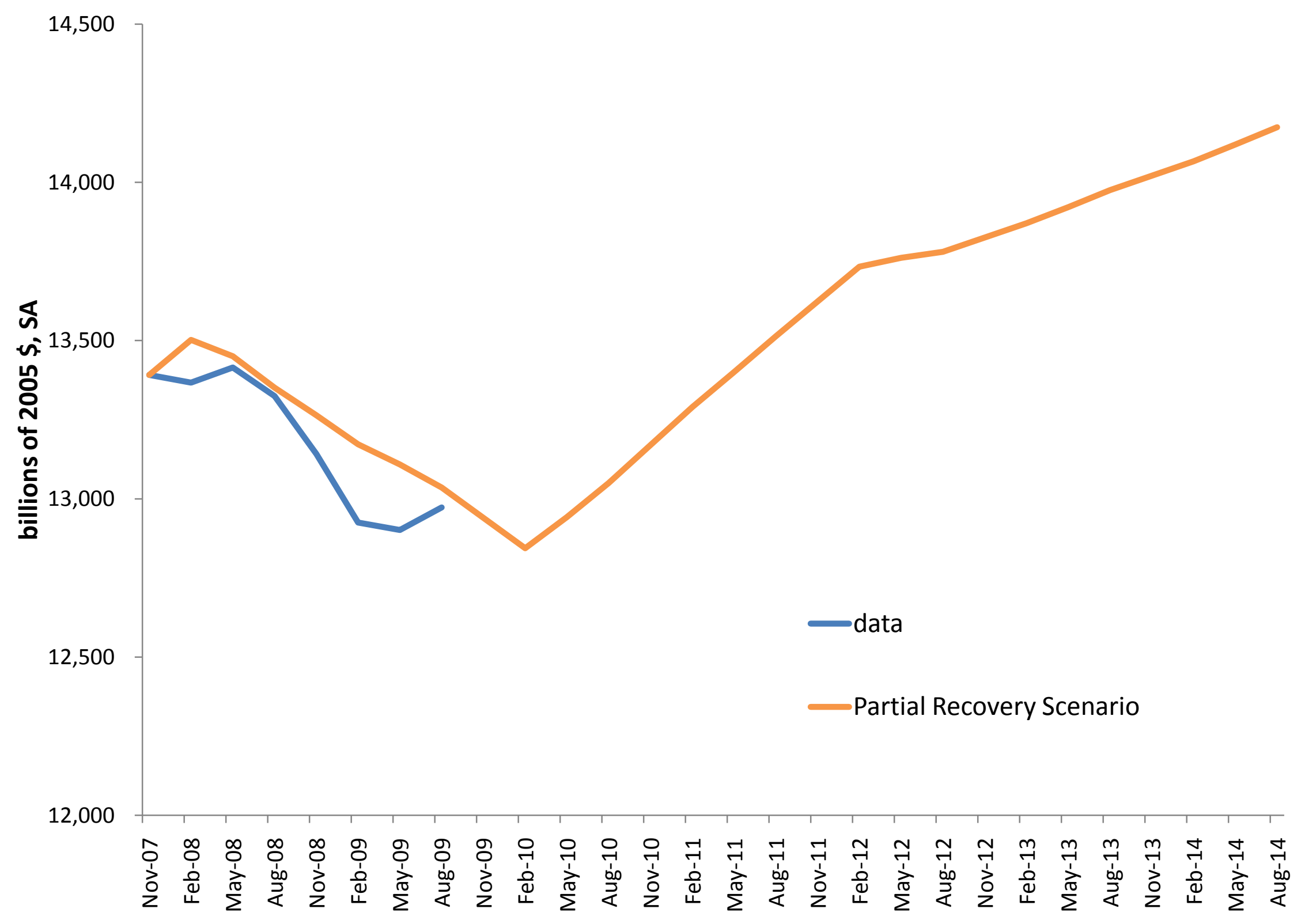


Fig 9. Labor Productivity and Labor Distortions in Three Recessions

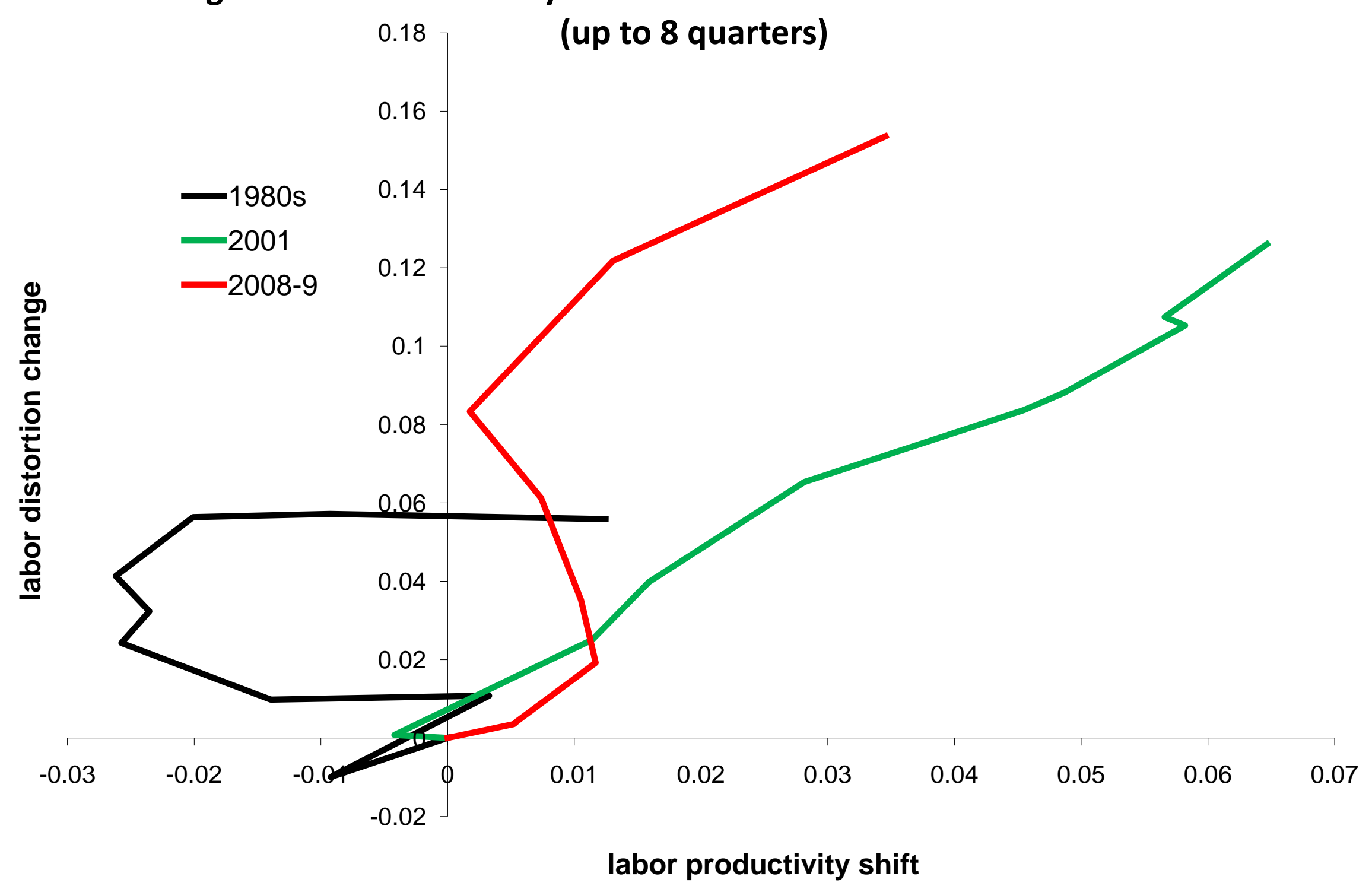




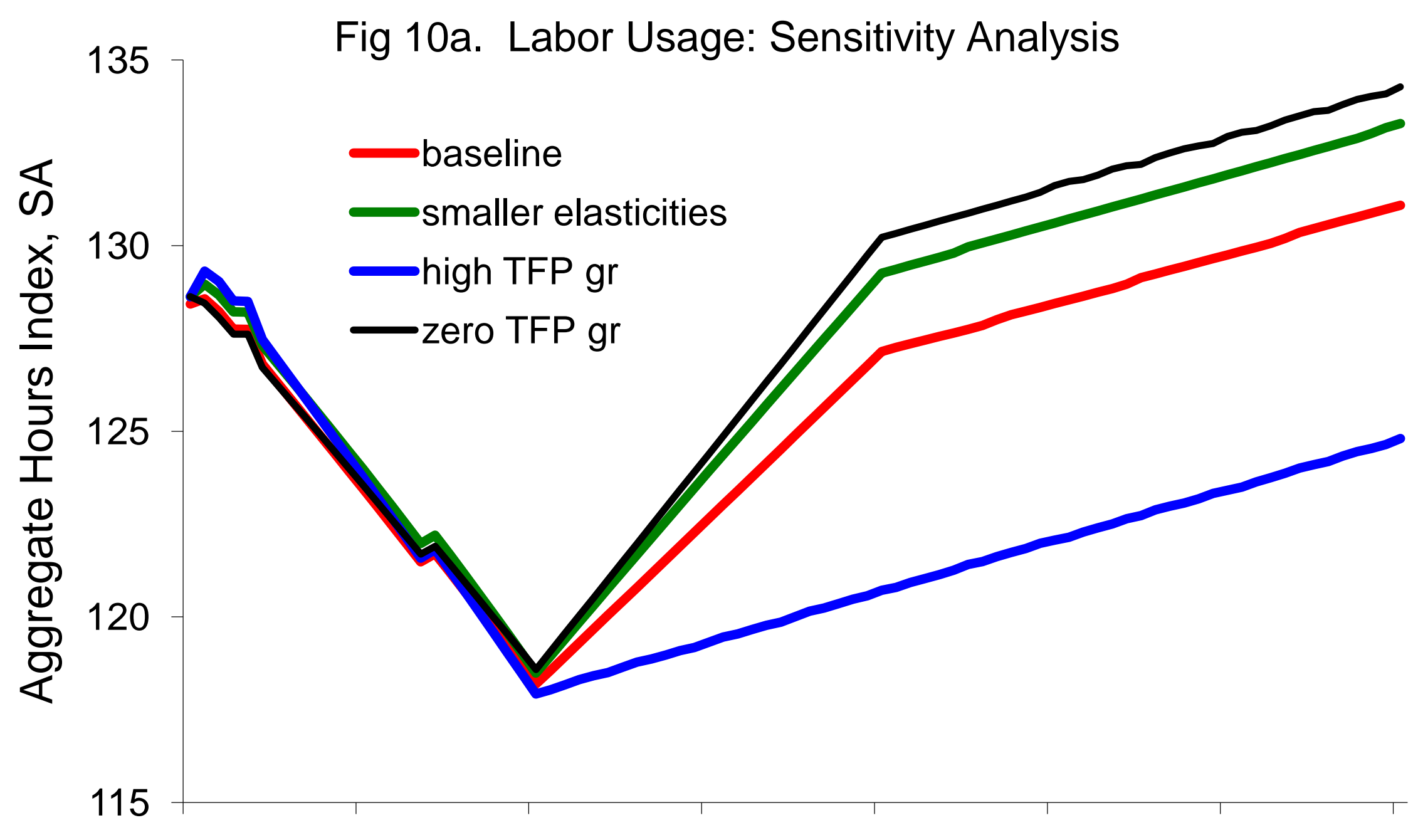

Dec-07 Dec-08 Dec-09 Dec-10 Dec-11 Dec-12 Dec-13 Dec-14 


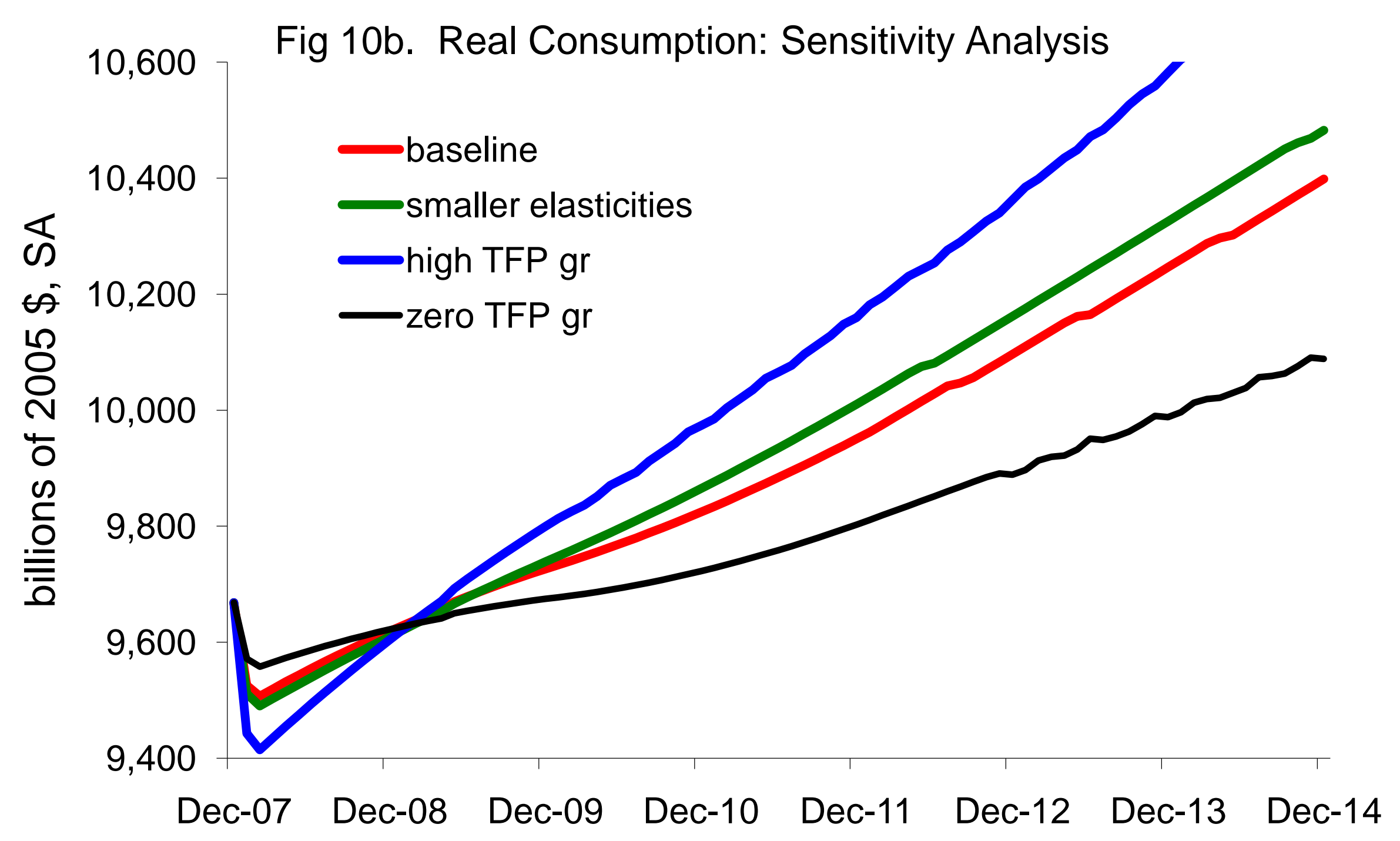




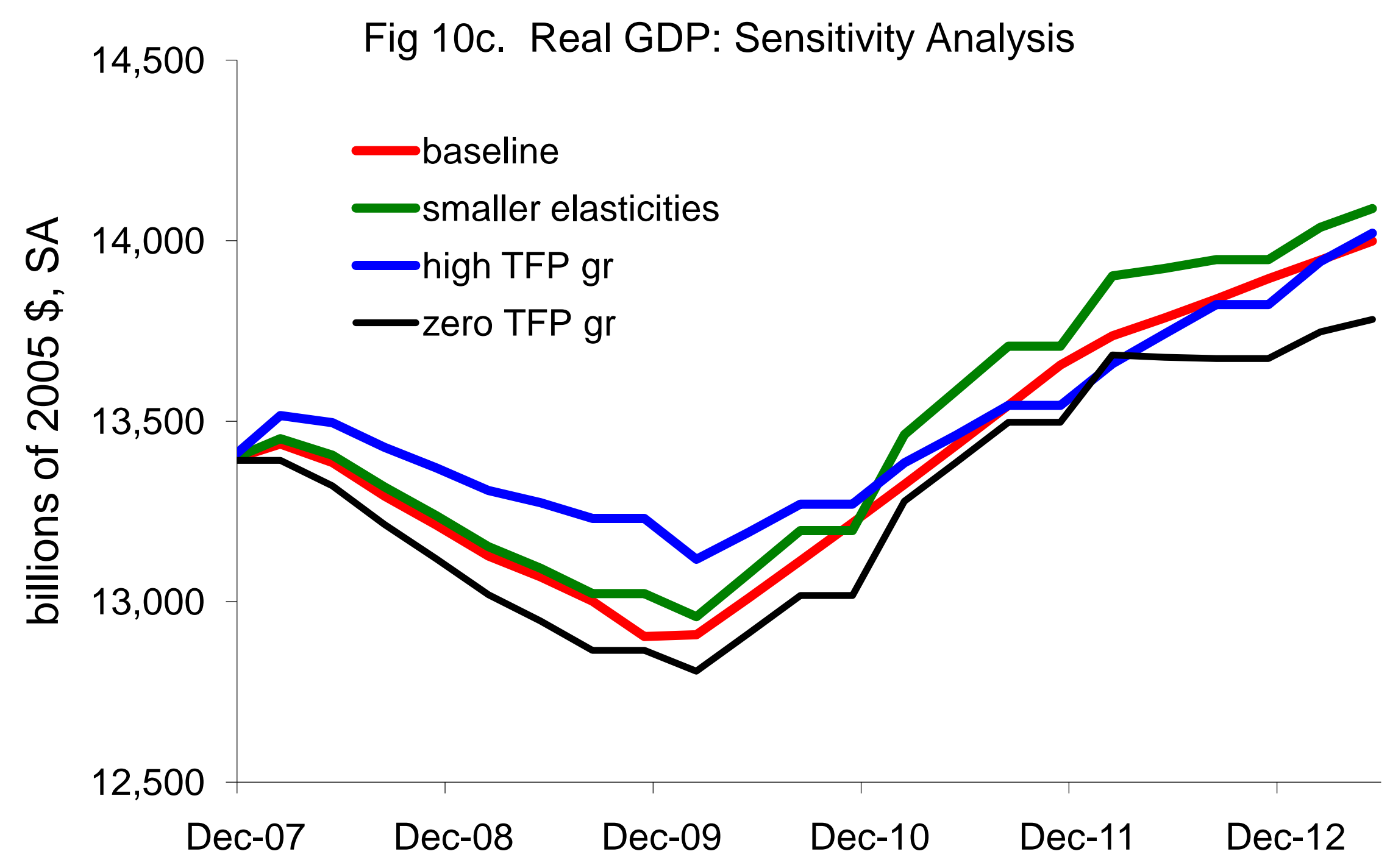




\section{References}

Abel, Andrew B., et al. "Options, the Value of Capital, and Investment." Quarterly Journal of Economics. 111(3), August 1996: 753-77.

Barro, Robert J. and Xavier Sala-i-Martin. Economic Growth. M.I.T. Press, 2003.

Chari, V. V., Patrick J. Kehoe, and Ellen R. McGrattan. "Business Cycle Accounting." Econometrica. 75(3), April 2007: 781-836.

Gali, Jordi, Mark Gertler, and J. David Lopez-Salido. "Markups, Gaps, and the Welfare Costs of Business Fluctuations." Review of Economics and Statistics. 89, February 2007: 44-59.

Hall, Robert E. "Macroeconomic Fluctuations and the Allocation of Time." Journal of Labor Economics. 15(1), Part 2 January 1997: S223-50.

Jermann, Urban J. and Vincenzo Quadrini. "Macroeconomic Effects of Financial Shocks.” NBER working paper no. 15338, September 2009.

Kydland, Finn and Edward C. Prescott. "Time to Build and Aggregate Fluctuations." Econometrica. 50(6), November 1982: 1345-70.

Lucas, Robert E., Jr. "Econometric Policy Evaluation: A Critique.” Carnegie-Rochester Series on Public Policy. 1, 1976: 19-46.

Mulligan, Casey B. "A Century of Labor-Leisure Distortions." NBER working paper no. 8774, February 2002.

Mulligan, Casey B. "What do Aggregate Consumption Euler Equations Say about the Capital Income Tax Burden.” American Economic Review. 94(2), Papers and Proceedings, May 2004: 166-70.

Mulligan, Casey B. "Public Policies as Specification Errors." Review of Economic Dynamics. 8(4), October 2005: 902-926.

Mulligan, Casey B. "What Caused the Recession of 2008? Hints from Labor Productivity." NBER working paper no. 14729, February 2009a.

Mulligan, Casey B. "Means-tested Mortgage Modification: Homes Saved or Income Destroyed?” NBER working paper no. 15821, August 2009b.

Prescott, Edward C. "Why Do Americans Work So Much More than Europeans?" Federal Reserve Bank of Minneapolis Quarterly Review. 28(1), July 2004: 2-14. 